\title{
Gestão estratégica da inovação sustentável: um estudo de caso em empresas industriais brasileiras
}

\section{Strategic management of sustainable innovation: a case study in brazilian industrial enterprises}

\author{
JORDANA MARQUES KNEIPP* \\ CLANDIA MAFFINI GOMES** \\ ROBERTO SCHOPRONI BICHUETI*** \\ LIARA DE OLIVEIRA MÜLLER **** \\ FRANCIES DIEGO MOTKE*****
}

\section{RESUMO}

A inovação sustentável pode estar relacionada a uma postura estratégica e sistemática das empresas no que se refere aos aspectos econômicos, sociais e ambientais, e não apenas a ações isoladas. A experiência de empresas líderes sugere que a incorporação da inovação sustentável em processos e sistemas é essencial para a obtenção de vantagem competitiva. Para tanto, o objetivo deste estudo consiste em caracterizar as especificidades das empresas industriais brasileiras no que diz respeito ao perfil, à gestão

* Universidade Federal de Santa Maria.Doutora pelo Programa de Pós-Graduação em Administração da Universidade Federal de Santa Maria, Professora no Departamento de Ciências Administrativas da Universidade Federal de Santa Maria. jordana.kneipp@ufsm.br

* Universidade Federal de Santa Maria. Doutora em Administração pela Universidade de São Paulo, Professora no Departamento de Ciências Administrativas da Universidade Federal de Santa Maria. clandia@smail.ufsm.br

*** Universidade Federal de Santa Maria. Doutor pelo Programa de Pós-Graduação em Administração da Universidade Federal de Santa Maria, Professora no Departamento de Ciências Administrativas da Universidade Federal de Santa Maria. robertobichueti@hotmail.com

*** Universidade Federal de Santa Maria. Acadêmica do Curso de Administração na Universidade Federal de Santa Maria. lica.muller@hotmail.com

***** Universidade Federal de Santa Maria. Doutorando no Programa de Pós-graduação da Universidade Federal de Santa Maria. fdmotke@gmail.com 
estratégica da inovação sustentável, ao modelo de negócios e ao desempenho empresarial. $\mathrm{O}$ estudo de natureza qualitativa teve como delineamento o estudo de casos múltiplos em quatro empresas brasileiras do setor industrial. Os resultados indicaram que nas empresas brasileiras entrevistadas está presente na concepção da estratégia e os esforços de inovação, tanto em produto como em processo, estão alinhados aos objetivos do desenvolvimento sustentável.

Palavras-chaves: Inovação. Sustentabilidade. Gestão Estratégica.

\section{Abstract}

Sustainable innovation can be related to a strategic and systematic position of companies regarding economic, social and environmental aspects, and not just isolated actions. The experience of leading companies suggests that incorporating sustainable innovation into processes and systems is essential to gain competitive advantage. Therefore, the objective of this study is to characterize the specificities of Brazilian industrial companies with regard to the profile, strategic management of sustainable innovation, business model and business performance. The study of a qualitative nature was based on the study of multiple cases in four Brazilian companies in the industrial sector. The results indicated that the Brazilian companies interviewed are present in the design of the strategy and the innovation efforts, both in product and in process, are aligned with the objectives of sustainable development.

Key-words: Innovation. Sustainability. Strategic management.

\section{INTRODUÇÃo}

As empresas vêm percebendo a importância da adoção de uma gestão estratégica da inovação sustentável a fim de atender aos condicionantes do mundo globalizado e obter um desempenho empresarial superior. A legislação e a própria sociedade vêm exigindo das organizações que a inovação em produtos, serviços, processos e modelos de negócios seja acompanhada pela responsabilidade com o desenvolvimento sustentável para minimizar possíveis impactos negativos dos processos industriais.

A fim de atender aos condicionantes socioambientais do ambiente de negócios, faz-se necessário que o desenvolvimento susten- 
tável esteja alinhado à inovação no sistema de mercado, de modo que os empresários busquem alcançar objetivos ambientais e/ou sociais por meio de produtos de qualidade superior ou processos aperfeiçoados no mercado de clientes tradicionais (SCHALTEGGER; WAGNER, 2011). Os novos valores empresariais desenvolvidos a partir de uma postura estratégica sustentável contemplam essencialmente a implementação de ideias inovadoras.

O desafio da inovação não deve ser exclusivamente econômico, mas também estar relacionado às mudanças sociais induzidas pela atividade inovadora e suas consequências na sustentabilidade ambiental e social (SMITH; VOß; GRIN, 2010).

Diante do exposto, é possível perceber que a inovação sustentável pode estar relacionada a uma postura estratégica e sistemática da empresa no que se refere aos aspectos econômicos, sociais e ambientais, e não apenas a ações isoladas, como o desenvolvimento de novos processos e produtos ambientalmente corretos. As empresas que mais contribuem para o desenvolvimento sustentável possuem soluções para os problemas ambientais e sociais, fornecem produtos ambiental e socialmente superiores e suas inovações influenciam o mercado de massa e a sociedade de forma substancial (SCHALTEGGER; WAGNER, 2011).

A experiência de empresas líderes sugere que a incorporação da inovação sustentável em processos e sistemas é essencial para a obtenção de vantagem competitiva, porém pode representar uma ação difícil e demorada, tendo em vista a necessidade de integrar estrategicamente a política organizacional (CHARTER; CLARK, 2007).

A inovação como propulsora da sustentabilidade requer mudanças no contexto empresarial e está relacionada a um modelo de negócios que contempla de forma estratégica a prosperidade econômica, o bem-estar social e a preservação ambiental.

Tendo como base a premissa de que a gestão empresarial fundamenta-se em decisões gerenciais derivadas de visões e estratégias corporativas que dão forma ao modelo de negócios e ao desenvolvimento organizacional, a orientação contínua de uma empresa para a inovação e a sustentabilidade requer modificações em seu modelo de negócios a fim de permitir o gerenciamento de 
atividades sociais e ambientais de forma sistemática (SCHALTEGGER; LÜDEKE-FREUND; HANSEN, 2012).

O modelo de negócios descreve a lógica de criação de valor de uma empresa, evidenciando a forma de obtenção dos seus lucros, especificando a sua posição na cadeia de valor (CHESBROUGH; ROSENBLOOM, 2002) e expõe, também, o conteúdo das transações, a estrutura e a governança de criação de valor da empresa por meio da exploração de oportunidades de negócios (AMIT; ZOTT, 2001).

A gestão estratégica da inovação sustentável e as possíveis modificações no modelo de negócios podem influenciar o desempenho empresarial. Diversos estudos como de Gunday et al. (2011), Lopez-Valeiras, Gomez-Conde e Naranjo-Gil (2015) e Wagner (2010) têm associado as temáticas da inovação e da sustentabilidade ao desempenho empresarial.

Na visão de Lopez-Valeiras, Gomez-Conde e Naranjo-Gil (2015), há um interesse cada vez maior no âmbito acadêmico, empresarial e político no que tange à relação entre a inovação sustentável e o desempenho empresarial.

A inovação sustentável contribui para a sustentabilidade do negócio, uma vez que, potencialmente, possui um efeito positivo nos resultados financeiros, sociais e ambientais de uma empresa (AGUILERA-CARACUEL; ORTIZ-DE-MANDOJANA, 2013).

Lopez-Valeiras, Gomez-Conde e Naranjo-Gil (2015) destacam a necessidade de pesquisas que forneçam mais evidências sobre a ligação entre a inovação sustentável e o desempenho organizacional. Na visão dos autores, embora a literatura sugira que a gestão da inovação sustentável pode ser uma fonte importante de benefícios para as empresas, os resultados empíricos ainda não são conclusivos.

A partir do exposto, é possível perceber que a gestão estratégica da inovação sustentável de empresas industriais pode ocasionar reflexos no modelo de negócios e no desempenho empresarial.

Tendo em vista a importância de uma gestão estratégica da inovação sustentável e a existência de uma possível relação com o modelo de negócios e o desempenho empresarial, alguns questionamentos emergem: De que maneira as empresas que atuam em ambientes cada vez mais complexos modificam seus modelos de negócios a partir da adoção de uma gestão estratégica da inovação sustentável? De que forma a 
gestão estratégica da inovação sustentável se relaciona com o desempenho empresarial?

A partir desses questionamentos, o objetivo do estudo consiste em caracterizar as especificidades das empresas industriais brasileiras no que se refere ao perfil, à gestão estratégica da inovação sustentável, ao modelo de negócios e ao desempenho empresarial.

\section{GESTÃo ESTRATÉGICA DA INOVAÇÃo SUSTENTÁVEL}

A adoção de uma estratégia de inovação sustentável pode propiciar ganhos em competitividade para as organizações, tendo em vista que o desenvolvimento de novos produtos, processos e formas de gestão que contemplem as premissas da sustentabilidade pode colocar a organização em uma posição de destaque perante os stakeholders, contribuindo para um desempenho empresarial superior.

A estratégia de inovação sustentável pode ser definida como a criação de algo novo que propicia a melhoria no desempenho nas três dimensões do desenvolvimento sustentável: social, ambiental e econômica. Tais melhorias não se restringem a mudanças tecnológicas, podendo estar relacionadas a modificações em processos, práticas operacionais, modelos de negócios, pensamento e sistemas empresariais (SZEKELY; STREBEL, 2012).

Eiriz, Faria e Barbosa (2013) propõem uma tipologia de estratégia de inovação, tendo como base o ciclo de vida empresarial. A taxonomia apresentada pelos autores é desenvolvida a partir da discussão referente às modificações nas decisões de inovação ao longo do tempo e nos diferentes estágios de crescimento das empresas. Desse modo, as estratégias de inovação são classificadas em termos do tipo de inovação (produto e processo) e de seu grau de novidade (incremental e radical), sendo identificadas quatro categorias: desenvolvimento de produtos, aprendizado pela experiência, descoberta e reestruturação.

Por sua vez, Schaltegger, Lüdeke-Freund e Hansen (2012), ao analisarem as estratégias para a sustentabilidade, adotaram em seu estudo a classificação defensiva, acomodativa e proativa.

Para os autores, o comportamento estratégico defensivo refere-se muitas vezes a uma reação das empresas que visa a evitar custos 
e restrições, sendo que os gerentes lidam com as questões da sustentabilidade de uma forma restrita e reativa. A estratégia acomodativa integra os objetivos ambientais ou sociais na maioria dos processos do negócio e em parte dos produtos, no entanto, esses objetivos não estão relacionados à lógica de geração de receita ou ao negócio principal da empresa. Por fim, a estratégia proativa integra os objetivos ambientais ou sociais na lógica central do negócio, visando contribuir para o desenvolvimento sustentável da economia e da sociedade (SCHALTEGGER; LÜDEKE-FREUND; HANSEN, 2012).

Complementando essa visão, Szekely e Strebel (2012) destacam que o desenvolvimento de novos produtos, serviços e processos internos integrando aspectos ambientais, sociais e econômicos tem ocorrido em grande parte de forma incremental e se relaciona principalmente a questões ambientais e econômicas, com menor ênfase nos aspectos sociais.

Uma estratégia de inovação radical para a sustentabilidade ocorre por meio de uma mudança sistêmica no pensamento da sociedade. A transformação das cadeias de suprimentos empresariais a partir da incorporação da sustentabilidade exige uma visão sistêmica dos impactos de produtos, serviços, processos e operações, incluindo questões sociais, como condições de trabalho, saúde e equidade humana; questões ambientais, como compra de matérias-primas, processos de fabricação e descarte; e questões econômicas, como competitividade e participação no mercado (SZEKELY; STREBEL, 2012).

A postura estratégica para a inovação sustentável irá direcionar as ações empresariais, por meio do desenvolvimento de novos produtos, serviços, tecnologias e processos que integrem elementos econômicos, sociais e ambientais.

A gestão da inovação sustentável estimula as empresas a aprenderem novas abordagens e a abandonarem antigas práticas, tendo em vista que envolve o trabalho com diferentes componentes do conhecimento, como novas tecnologias, novos mercados, novas condições ambientais e regulamentações (SEEBODE; JEANRENAUD; BESSANT, 2012).

O grande desafio das organizações está em inovar a partir da perspectiva do desenvolvimento sustentável, agregando valor aos 
produtos e processos e contribuindo para a minimização de impactos socioambientais decorrentes da atividade industrial.

Boons (2009) diz que as inovações sustentáveis precisam ir além dos níveis incrementais, tendo em vista que o desenvolvimento sustentável requer a transformação dos sistemas de produção e de consumo.

Desse modo, pode-se perceber a necessidade de a inovação sustentável perpassar o ambiente de negócios e ser valorizada pela sociedade, a fim de que as empresas possam investir em níveis de inovação radical, construindo-se uma nova lógica em prol da sustentabilidade.

Bocken et al. (2014) identificaram uma gama de exemplos de mecanismos e soluções que podem contribuir para a inovação do modelo de negócios para a sustentabilidade a partir de uma revisão da literatura e de práticas empresariais, propondo oito arquétipos, agrupados nas dimensões da inovação tecnológica, social e organizacional, a fim de descrever mecanismos e soluções que possam contribuir para a sustentabilidade, que são: 1) maximizar eficiência energética e material; 2) criar valor a partir do desperdício; 3) substituir por processos renováveis e naturais; 4) entregar funcionalidade ao invés de propriedade; 5) adotar papel de liderança; 6) incentivar a suficiência; 7) adaptar os negócios para a sociedade/meio ambiente; e 8) desenvolver escala de soluções.

A gestão estratégica da inovação sustentável cada vez mais ganha destaque no contexto dos negócios e, apesar de diversos estudos abordarem a sua aplicação no ambiente empresarial, ainda existem lacunas no que se refere aos reflexos no modelo de negócios e no desempenho empresarial, temas tratados na sessão seguinte.

\section{MODELO DE NEGÓCIOS E DESEMPENHO EMPRESARIAL}

A literatura sobre modelo de negócios tem crescido consideravelmente desde o final da década de 1990, de maneira que parece haver uma concordância por parte dos autores de que um modelo de negócios é uma representação da forma como a empresa faz negócios, ou seja, criar e entregar valor ao cliente, de modo a gerar receitas e alcançar uma posição competitiva sustentável (TARAN, 2011; TARAN; BOER; LINDGREN, 2015). 
O conceito de modelo de negócios reflete a estrutura organizacional e a forma como a empresa se comunica com seus stakeholders e gera valor para os clientes e para a sociedade. Para Chesbrough e Rosenbloom (2002, p. 533), o modelo de negócios descreve a "lógica de criação de valor de uma empresa, ilustrando a forma de obtenção dos seus lucros e especificando a sua posição na cadeia de valor". Ainda "expõe o conteúdo das transações, a estrutura e a governança de criação de valor da empresa por meio da exploração de oportunidades de negócios" (AMIT; ZOTT, 2001, p. 494-495).

Bocken et al. (2014) definem um modelo de negócios a partir de três elementos principais: proposta de valor: produto/serviço, segmentos de clientes e relacionamentos; criação de valor e entrega: atividades chave, recursos, canais, parceiros, tecnologia; captura de valor: estrutura de custos e fonte de receitas.

A criação de valor é o coração de qualquer modelo de negócio, tendo em vista que as empresas normalmente capturam valor, aproveitando novas oportunidades de negócios, novos mercados e novas fontes de receita (BOCKEN et al. 2014; BELTRAMELLO, HAIE-FAYLE; PILAT, 2013; TEECE, 2010). Enquanto a proposta de valor está geralmente relacionada com a oferta de produtos e serviços para gerar retorno econômico, em um negócio sustentável, a proposta de valor resultaria em valor ecológico e/ou social mensurável em conjunto com valor econômico (BOCKEN et al. 2014; BOONS; LÜDEKE-FREUND, 2013). Por fim, a captura de valor relaciona-se à forma de obtenção de receitas a partir do fornecimento de bens, serviços ou informações para os usuários e clientes (BOCKEN et al. 2014; TEECE, 2010).

A concorrência global tem forçado as empresas a repensar os seus modelos de negócios com maior frequência, tendo em vista que inovar exclusivamente em novos produtos e atender a mercados locais não é suficiente para sustentar de forma competitiva e garantir a sobrevivência da empresa (TARAN; BOER; LINDGREN, 2015).

Tendo como base o conceito genérico de modelo de negócios e os seus principais componentes, é necessário entender que a orientação dos negócios para a sustentabilidade de forma contínua pode requerer a adaptação ou até mesmo a mudança radical do modelo de negócios da empresa (SCHALTEGGER; LÜDEKE-FREUND; HAN- 
SEN, 2012). Para os autores, a inovação do modelo de negócios visa garantir o sucesso empresarial e contribuir para o desenvolvimento sustentável.

Ainda para Schaltegger, Lüdeke-Freund e Hansen (2012), um modelo de negócios orientado para a sustentabilidade deve ser gerenciado ativamente a fim de conquistar clientes e criar valor social por meio da integração de atividades sociais, ambientais e de negócios.

Boons et al. (2013) defendem que qualquer alteração significativa na lógica econômica dominante envolve a aplicação de novos modelos de negócios pelos atores sociais que buscam promover ideias, desenvolver diferentes tipos de inovações e implementar novas práticas em prol da sustentabilidade. Complementando, os autores afirmam que, nessa perspectiva, cada uma das dimensões do modelo de negócios precisa ser alterada: as proposições de valor devem refletir as verdadeiras necessidades dos cidadãos e a distribuição de receitas precisa ser definida em categorias não puramente econômicas, o que exige uma mudança fundamental na maneira pela qual as empresas se conectam entre si e com a sociedade.

No ano de 2012, uma pesquisa realizada pelo MIT Sloan Management Review, em parceria com o Boston Consulting Group (BCG), com mais de 2.600 executivos de uma ampla gama de indústrias de todo o mundo, sugeriu que as empresas que criam valor econômico devido a atividades e decisões de sustentabilidade são as que modificam os seus modelos de negócios, possuem o apoio da alta direção, a colaboração dos clientes e dos stakeholders externos (KIRON et al., 2013a; KIRON et al., 2013b).

O modelo de negócios contempla aspectos essenciais das empresas, como proposição de valor, cadeia de suprimentos, relacionamentos com clientes e modelo financeiro e, desse modo, pode ser modificado em função da adoção de gestão estratégica da inovação sustentável pelas empresas, impactando o desempenho empresarial.

As temáticas da inovação e da sustentabilidade têm sido comumente associadas ao desempenho empresarial em diversos estudos. O desempenho é um parâmetro usado para quantificar a "eficiência e/ou eficácia de uma ação passada” (NEELY; ADAMS, KENNERLEY et al., 2002, p. xii) e "a capacidade da organização em atingir 
seus objetivos, utilizando seus recursos de forma eficiente" (DAFT; MARCIC, 2004, p. 10).

Em relação ao desempenho inovador, Gunday et al. (2011) destacam que a literatura tem abordado a inovação com o objetivo de analisar as relações entre os tipos de inovação e o desempenho da empresa, de modo que há um grande número de estudos conceituais, sendo os estudos analíticos e empíricos relacionados ao assunto ainda limitados, tanto em quantidade como em profundidade da análise. Dessa forma, em sua pesquisa os autores analisam 184 empresas de manufatura da Turquia e destacam os efeitos da inovação nas diferentes dimensões do desempenho empresarial: desempenho inovador, de produção, de mercado e financeiro, revelando os efeitos positivos das inovações no desempenho empresarial.

No que tange ao desempenho sustentável, a proposta desenvolvida pela Global Reporting Initiative - GRI - representa um dos escopos mais abrangentes, sendo conhecida e utilizada mundialmente para fins de elaboração de relatórios de sustentabilidade pelas empresas, e suas diretrizes consistem no padrão mais amplamente usado mundialmente para a comunicação da sustentabilidade, de acordo com autores como Skouloudis, Evangelinos e Kourmousis (2009); Prado-Lorenzo, Gallego-Alvarez e Garcia-Sanchez (2009); Tsang, Welford e Brown (2009); Brown, De Jong e Levy (2009); Rasche, (2009); Levy, Szejnwald e De Jong (2010); Marimon et al. (2012).

As diretrizes propostas pela GRI dividem-se nas categorias econômica, ambiental e social. Cada categoria inclui informações sobre a forma de gestão e um conjunto correspondente de indicadores de desempenhos essenciais e adicionais. Os indicadores essenciais consideram aspectos relevantes à maioria das organizações, e os adicionais representam práticas emergentes ou tratam de temas que podem ser relevantes para determinadas organizações (GLOBAL REPORTING INITIATIVE, 2006).

Para Lopez-Valeiras, Gomez-Conde e Naranjo-Gil (2015), a influência da sustentabilidade corporativa no desempenho organizacional tem sido analisada nas últimas décadas em diversos estudos, como o de Wagner (2010), que analisa a relação entre a gestão da sustentabilidade e o desempenho econômico, elucidando que, a partir de medidas separadas para o desempenho social e ambiental, 
apenas o último tem um efeito direto sobre o desempenho econômico, enquanto que o primeiro possui um efeito moderado.

A inovação sustentável incorpora melhorias tecnológicas que podem propiciar a economia de energia, a minimização da poluição, a reciclagem de resíduos, o desenvolvimento de produtos verdes e a gestão ambiental corporativa. Esse tipo de inovação também contribui para a sustentabilidade do negócio, uma vez que, potencialmente, possui um efeito positivo nos resultados financeiros, sociais e ambientais de uma empresa (AGUILERA-CARACUEL; ORTIZ-DE-MANDOJANA, 2013).

A partir das temáticas apresentadas, busca-se analisar a gestão estratégica da inovação sustentável, o modelo de negócios e o desempenho em empresas industriais. Assim, a seguir é apresentado o método para o desenvolvimento do estudo.

\section{MÉTOdo do ESTUdo}

O estudo de natureza qualitativa teve como delineamento o estudo de casos múltiplos. Para Yin (2010, p. 39), "um estudo de caso é uma investigação empírica que investiga um fenômeno contemporâneo em profundidade e em seu contexto de vida real, especialmente quando os limites entre o fenômeno e o contexto não estão claramente evidentes". Complementando, Gil (2008, p. 57) destaca que "o estudo de caso é caracterizado pelo estudo profundo e exaustivo de um ou de poucos objetos, de maneira a permitir o seu conhecimento amplo e detalhado".

No presente estudo, investiga-se o fenômeno referente à gestão estratégica da inovação sustentável, ao modelo de negócios e ao desempenho empresarial em empresas industriais.

\subsection{Categorias de análise}

O Quadro 1 resume as dimensões e categorias de análise da etapa qualitativa do estudo. 
Quadro 1 - Categorias de análise da etapa qualitativa

\begin{tabular}{|c|c|}
\hline Categorias de Análise & Variáveis \\
\hline \multicolumn{2}{|c|}{ Gestão estratégica da inovação sustentável } \\
\hline \multicolumn{2}{|c|}{ Postura estratégica para a inovação sustentável } \\
\hline Postura estratégica & $\begin{array}{l}\text { Proativa em produto/processo; } \\
\text { Acomodativa em produto/processo; } \\
\text { Defensiva em produto/processo. }\end{array}$ \\
\hline \multicolumn{2}{|c|}{ Práticas de inovação sustentável } \\
\hline $\begin{array}{l}\text { Adaptação dos negó- } \\
\text { cios para a sociedade }\end{array}$ & $\begin{array}{l}\text { - Integração entre a empresa, as comunidades locais } \\
\text { e demais stakeholders para a geração de benefícios } \\
\text { sociais e ambientais. } \\
\text { - Mecanismos de interação da empresa com os } \\
\text { stakeholders. }\end{array}$ \\
\hline $\begin{array}{l}\text { Desenvolvimento de } \\
\text { soluções sustentáveis }\end{array}$ & $\begin{array}{l}\text { - Soluções sustentáveis para maximizar os benefícios } \\
\text { para a sociedade e o ambiente. } \\
\text { - Soluções de produtos e serviços que buscam redu- } \\
\text { zir o consumo e por conseguinte reduzir a produção. }\end{array}$ \\
\hline $\begin{array}{l}\text { Maximização da } \\
\text { eficiência energética, } \\
\text { hídrica e redução das } \\
\text { emissões }\end{array}$ & $\begin{array}{l}\text { - Práticas para melhorar a eficiência energética. } \\
\text { - Práticas para melhorar a eficiência hídrica. } \\
\text { - Práticas para reduzir as emissões da cadeia de } \\
\text { fornecimento. }\end{array}$ \\
\hline $\begin{array}{l}\text { Criação de valor, a } \\
\text { partir do desperdício }\end{array}$ & $\begin{array}{l}\text { - Eliminação do conceito de "resíduo", a partir da } \\
\text { transformação de fluxos de desperdícios existentes } \\
\text { em contribuição útil e valiosa para outra produção. } \\
\text { - Custos econômicos e ambientais são reduzidos por } \\
\text { meio da reutilização de material e transformação de } \\
\text { desperdício em valor. }\end{array}$ \\
\hline $\begin{array}{l}\text { Substituição por pro- } \\
\text { cessos renováveis e } \\
\text { naturais }\end{array}$ & $\begin{array}{l}\text { - Inovação em produtos e processos de produção } \\
\text { ao utilizar recursos e energia renováveis e conceber } \\
\text { novas soluções imitando os sistemas naturais. }\end{array}$ \\
\hline $\begin{array}{l}\text { Entrega de funcio- } \\
\text { nalidade ao invés de } \\
\text { propriedade }\end{array}$ & $\begin{array}{l}\text { - Alternativas para a substituição de produtos por } \\
\text { serviços - sistema de produto-serviço (Product-Servi- } \\
\text { ce System - PSS). } \\
\text { - Ações que busquem a criação e projeção de novas } \\
\text { necessidades sustentáveis que possam mudar o cur- } \\
\text { so dos atuais estilos de vida da população. }\end{array}$ \\
\hline
\end{tabular}




\begin{tabular}{|l|l|}
\hline Categorias de Análise & Variáveis \\
\hline $\begin{array}{l}\text { Adoção de papel de } \\
\text { liderança }\end{array}$ & $\begin{array}{l}\text { - Práticas para garantir o bem-estar dos stakeholders } \\
\text { (funcionários, clientes, fornecedores, acionistas). } \\
\text { - Sistemas de produção e fornecedores selecionados } \\
\text { para proporcionar benefícios ambientais e sociais. }\end{array}$ \\
\hline Modelo de Negócios & \multicolumn{2}{|l|}{$\begin{array}{l}\text { - Definição do modelo de negócios; } \\
\text { - Proposição de valor da empresa relacionada a cri- } \\
\text { tários econômicos, sociais e ambientais; }\end{array}$} \\
\hline $\begin{array}{l}\text { Grau de inovação do } \\
\text { modelo de negócios }\end{array}$ & $\begin{array}{l}\text { - Modificações do modelo de negócios, a partir das } \\
\text { atividades e decisões de sustentabilidade. }\end{array}$ \\
\hline $\begin{array}{l}\text { Cadeia de } \\
\text { suprimentos }\end{array}$ & $\begin{array}{l}\text { - Envolvimento dos fornecedores na gestão sustentá- } \\
\text { vel da cadeia de suprimentos. }\end{array}$ \\
\hline $\begin{array}{l}\text { Relacionamento com } \\
\text { os clientes }\end{array}$ & $\begin{array}{l}\text { - Relacionamento com o cliente considerando os } \\
\text { desafios da sustentabilidade. }\end{array}$ \\
\hline \multicolumn{2}{|l|}{$\begin{array}{l}\text { Modelo financeiro } \\
\text { buição adequada de custos e benefícios econômicos } \\
\text { entre os stakeholders da empresa; } \\
\text { - O modelo financeiro é responsável pelos impactos } \\
\text { ecológicos e sociais da empresa. }\end{array}$} \\
\hline Desempenho empresarial \\
\hline $\begin{array}{l}\text { Desempenho empre- } \\
\text { sarial }\end{array}$ & $\begin{array}{l}\text { Formas de mensuração do desempenho empresarial. } \\
\text { Relação do desempenho com os investimentos em } \\
\text { sustentabilidade. }\end{array}$ \\
\hline
\end{tabular}

Fonte: Elaborado a partir de Schaltegger, Lüdeke-Freund e Hansen (2012); Eiriz, Faria e Barbosa (2013); Bocken et al. (2014); Boons e Lüdeke-Freund (2013); Kiron et al., (2013a); Taran e Boer (2015); Gunday et al. (2011).

Tendo como base as dimensões e categorias de análise, buscou-se analisar a gestão estratégica para a inovação sustentável, o modelo de negócios e o desempenho empresarial em empresas industriais.

\subsection{Procedimentos para a coleta e análise dos dados}

Segundo Yin (2010), o estudo de caso requer a utilização de múltiplas fontes de evidências que convergem e cujos resultados se beneficiam de proposições teóricas anteriores à coleta de dados e análise. Na concepção do autor, as principais fontes de evidências 
usadas para realizar estudos de caso são documentação, registros em arquivos, entrevistas, observação direta, observação participante e artefatos físicos.

Para fins deste estudo, foram adotadas a entrevista e a análise de documentação como principais fontes de evidências. De acordo com Yin (2010), uma das mais importantes fontes de informações para o estudo de caso são as entrevistas, que podem ser classificadas em três tipos: em profundidade; focada ou levantamento formal.

Buscando atender aos objetivos do estudo, foram realizadas entrevistas com quatro empresas brasileiras que pertenciam ao setor industrial e possuíam indícios de inovação.

Para a realização das entrevistas, foi utilizado um protocolo de entrevista ancorado nas categorias de análise do Quadro 6, o qual foi usado pelo pesquisador como um meio de orientação, pautando-se nas questões inerentes às categorias de análise e variáveis estudadas.

As entrevistas foram gravadas com a devida autorização dos respondentes e posteriormente transcritas, buscando uma melhor compreensão do seu conteúdo. Sete entrevistas foram realizadas de forma presencial e uma foi feita com recursos de tecnologia, por meio do Skype.

Para a análise dos dados, foi utilizado o método de análise de conteúdo, que, segundo as proposições de Bardin (2011), trata-se do desvendamento de significações de diferentes tipos de discursos, baseando-se na inferência ou dedução, mas que, simultaneamente, respeita critérios específicos propiciadores de dados em frequência, em estruturas temáticas, entre outros.

$\mathrm{Na}$ análise da documentação, foram buscados conteúdos relativos às temáticas de inovação e sustentabilidade que complementassem as evidências obtidas nas entrevistas. Utilizou-se o software NVivo 8.0 para auxílio na análise dos dados, por meio do qual foi possível codificar, filtrar, fazer buscas, questionar e categorizar os dados para responder ao problema de pesquisa.

\section{APRESENTAÇ̃̃o E disCUSSÃo doS RESULTADOS}

Os dados foram obtidos em quatro empresas industriais do Brasil, denominadas, para fins deste estudo, como empresas Alfa, Beta, Gama e Delta. Os resultados são descritos a partir de quatro categorias de análise: caracterização das empresas, gestão estratégica para a inovação sustentável, modelo de negócios e desempenho empresarial. 
Foram entrevistados os responsáveis pelas atividades de inovação e/ou sustentabilidade indicados pela direção de suas respectivas organizações, cujo perfil detalhado pode ser consultado no Apêndice D. A visão de profissionais que ocupam cargos de destaque nas organizações estudadas, e que possuem um largo conhecimento da empresa e formação apropriada para contribuir com a pesquisa, permitiu a comparação dos dados a partir de diversas perspectivas.

\subsection{Caracterização das empresas}

O Quadro 2 apresenta uma síntese das principais características das empresas pesquisadas, considerando-se os seguintes aspectos: ano de fundação, localização, setor de atividade, número de funcionários, faturamento bruto em 2014, tipo e origem do capital, divulgação de relatórios de sustentabilidade, principal tipo de inovação e certificações.

\section{Quadro 2 - Caracterização das empresas brasileiras analisadas}

\begin{tabular}{|c|c|c|c|c|}
\hline $\begin{array}{l}\text { Características } \\
\text { Organizacionais }\end{array}$ & Empresa Alfa & Empresa Beta & $\begin{array}{l}\text { Empresa } \\
\text { Gama }\end{array}$ & Empresa Delta \\
\hline Ano de fundação & 1946 & 2002 & 2003 & 1924 \\
\hline Localização & Sumaré (SP) & $\begin{array}{l}\text { Brasil, Alema- } \\
\text { nha e } \\
\text { Estados Unidos }\end{array}$ & $\begin{array}{l}\text { Santa Cruz } \\
\text { (RS) }\end{array}$ & Santa Cruz (RS) \\
\hline Setor de atividade & Químico & Químico & Tecnológico & Saúde e Educação \\
\hline $\begin{array}{l}\text { Número de funcio- } \\
\text { nários }\end{array}$ & $\begin{array}{l}4.200 \text { funcio- } \\
\text { nários }\end{array}$ & $\begin{array}{l}8.126 \text { funcio- } \\
\text { nários }\end{array}$ & $\begin{array}{l}215 \text { funcioná- } \\
\text { rios }\end{array}$ & 550 funcionários \\
\hline $\begin{array}{l}\text { Receita operacional } \\
\text { bruta }\end{array}$ & R\$ 3 bilhões & R\$ 53 bilhões & $\mathrm{R} \$ 41$ milhões & R\$ 110,8 milhões \\
\hline Tipo de capital & $\begin{array}{l}\text { Capital } \\
\text { fechado }\end{array}$ & Capital aberto & $\begin{array}{l}\text { Capital fe- } \\
\text { chado }\end{array}$ & Capital fechado \\
\hline $\begin{array}{l}\text { Origem do capital } \\
\text { controlador }\end{array}$ & Estrangeira & Nacional & Nacional & Nacional \\
\hline $\begin{array}{l}\text { Divulgam relatório de } \\
\text { sustentabilidade }\end{array}$ & Sim & Sim & Não & Não \\
\hline $\begin{array}{l}\text { Tipo de inovação } \\
\text { principal }\end{array}$ & $\begin{array}{l}\text { Em produto e } \\
\text { processo }\end{array}$ & $\begin{array}{l}\text { Em produto e } \\
\text { processo }\end{array}$ & $\begin{array}{l}\text { Em produto e } \\
\text { processo }\end{array}$ & $\begin{array}{l}\text { Em produto e } \\
\text { processo }\end{array}$ \\
\hline Certificações & $\begin{array}{l}\text { ISO } 9001 \text { e } \\
\text { ISO } 14001\end{array}$ & $\begin{array}{l}\text { ISO 9001, } \\
\text { ISO-14001, } \\
\text { OHSAS-18001, } \\
\text { Verdes, ISO/TS } \\
16949, \text { RCMS, } \\
\text { ISO 17025, ISO } \\
50001\end{array}$ & ISO 9001 & ISO 9001 \\
\hline
\end{tabular}


A análise das principais características organizacionais denota a existência de duas empresas com larga experiência no mercado e duas empresas mais jovens. As empresas atuam em setores distintos, sendo que duas delas pertencem ao setor químico, uma ao setor tecnológico e outra aos setores de saúde e educação.

Percebe-se que os resultados serão apresentados sob a perspectiva de duas empresas maduras que acompanharam diversas mudanças no ambiente competitivo ao longo dos últimos anos, bem como, maiores exigências por parte da sociedade relativas à inovação e sustentabilidade e de duas empresas que nasceram nesse ambiente de maiores exigências e competitividade. As empresas pertencem a setores nos quais a inovação e a sustentabilidade possuem importância estratégica para a sua sobrevivência e competitividade.

Tendo como base a receita operacional bruta e o número de funcionários, as empresas Alfa e Beta caracterizam-se como de grande porte, a empresa Delta classifica-se como média-grande e a empresa Gama possui porte médio. Foi possível verificar que as organizações são de portes distintos, o que pode contribuir para a análise sob diferentes óticas dos investimentos em inovação sustentável e os reflexos no modelo de negócios e no desempenho empresarial.

Apenas a empresa Beta possui capital aberto, e a empresa Alfa tem origem estrangeira do seu capital controlador.

Duas empresas divulgam relatórios de sustentabilidade, elucidando a preocupação em apresentar de forma pública os investimentos empresariais.

Todas as empresas inovam tanto em produto com em processo, caracterizando que a atividade de inovação perpassa os diversos processos empresariais e também em novos produtos.

Todas as organizações possuem a certificação de qualidade ISO 9001, sendo que apenas as empresas Alfa e Beta têm a certificação ambiental ISO 14001. Esse fato representa uma preocupação inicial com os requisitos da qualidade para um posterior investimento em normativas especificamente ambientais.

Desse modo, em virtude das diferenças observadas, é possível ressaltar que as organizações pesquisadas possuem o perfil necessário para atender aos objetivos propostos pelo estudo, sendo possível analisar o comportamento no que tange à gestão estratégica da inovação sustentável, ao modelo de negócios e ao desempenho empresarial por meio de realidades distintas, o que contribuirá para um maior aprofundamento teórico e empírico no que tange 


\subsection{Gestão estratégica da inovação sustentável}

A gestão estratégica da inovação sustentável foi analisada com base em duas dimensões, uma que trata da postura estratégica e outra que se refere às práticas para a inovação sustentável.

O Quadro 3 resume as principais evidências encontradas no que se refere à postura estratégica para a inovação sustentável.

\section{Quadro 3 - Postura estratégica para a inovação sustentável}

\begin{tabular}{|c|c|c|}
\hline \multicolumn{3}{|c|}{ Postura Estratégica para a Inovação Sustentável } \\
\hline Empresa & Variáveis & Evidências \\
\hline \multirow{4}{*}{ Alfa } & $\begin{array}{l}\text { Inovação } \\
\text { em produto } \\
\text { e processo }\end{array}$ & $\begin{array}{l}\text { "Tudo direcionado por produto. Temos inovação de processo, mas } \\
\text { ela está focada na promessa de inovação do produto." }\end{array}$ \\
\hline & $\begin{array}{l}\text { Grau incre- } \\
\text { mental de } \\
\text { novidade }\end{array}$ & $\begin{array}{l}\text { "É incremental, mas tem uma razão lógica e importante. [...] Você tem } \\
\text { um core enorme que gera recursos para tentar coisas novas, só que } \\
\text { esse core tem que ter manutenção, o concorrente está batendo na porta } \\
\text { o tempo inteiro, com preço mais agressivo e com desempenho." }\end{array}$ \\
\hline & $\begin{array}{l}\text { Nível de } \\
\text { sustenta- } \\
\text { bilidade } \\
\text { proativa }\end{array}$ & $\begin{array}{l}\text { "É proativa mesmo, e começa no controle do nível molecular do ne- } \\
\text { gócio. [...]. Seguimos todo o conjunto de políticas internas e olhamos } \\
\text { todo o ambiente regulatório local. Então, no processo de introdução } \\
\text { de novos produtos temos um grande processo que se chama LCM } \\
\text { (Life Cycle Management) onde fazemos todas essas análises." }\end{array}$ \\
\hline & $\begin{array}{l}\text { Governança } \\
\text { estratégi- } \\
\text { ca para a } \\
\text { sustentabili- } \\
\text { dade }\end{array}$ & $\begin{array}{l}\text { "A empresa criou duas posições dedicadas à sustentabilidade no } \\
\text { board executivo global. Os projetos com apelo sustentável passaram } \\
\text { de } 5 \% \text { para } 28 \% \text {, nos últimos cinco anos. Desde 2014, temos uma } \\
\text { governança estratégica para discussão e implementação do Plano } \\
\text { de Sustentabilidade." }\end{array}$ \\
\hline \multirow{4}{*}{ Beta } & $\begin{array}{l}\text { Inovação } \\
\text { em produto } \\
\text { e processo }\end{array}$ & $\begin{array}{l}\text { "Temos grandes projetos que poderiam ser caracterizados mais } \\
\text { como processo, mas tem um conjunto muito grande de projetos } \\
\text { para inovação em produto." }\end{array}$ \\
\hline & $\begin{array}{l}\text { Grau incre- } \\
\text { mental de } \\
\text { novidade }\end{array}$ & $\begin{array}{l}\text { "Temos um conjunto importante ligado ao core, que são mais incre- } \\
\text { mentais e muitos projetos adjacentes, que é quando vou atuar no } \\
\text { mesmo mercado com o mesmo produto, através de um processo } \\
\text { um pouco diferente ou atingir mercados que eu não atingia." }\end{array}$ \\
\hline & $\begin{array}{l}\text { Nível de } \\
\text { sustenta- } \\
\text { bilidade } \\
\text { proativa }\end{array}$ & $\begin{array}{l}\text { "Buscamos integrar a sustentabilidade na estratégia de negócios } \\
\text { para buscar diferenciação para encontrar melhores formas de fazer } \\
\text { negócio e contribuir mais para a sustentabilidade ou para a socie- } \\
\text { dade em geral." }\end{array}$ \\
\hline & $\begin{array}{l}\text { Matriz de } \\
\text { materialida- } \\
\text { de e macro } \\
\text {-objetivos } \\
\text { estratégicos }\end{array}$ & $\begin{array}{l}\text { "Temos uma Matriz de Materialidade, que considera o impacto } \\
\text { sobre diversos temas versus a relevância para as partes interessa- } \\
\text { das. Na matriz, dos } 29 \text { aspectos avaliados, } 17 \text { foram considerados } \\
\text { materiais, por estarem nos quadrantes críticos ou de alta criticida- } \\
\text { de e estes foram consolidados em } 10 \text { macro-objetivos estratégicos } \\
\text { para o desenvolvimento sustentável." }\end{array}$ \\
\hline
\end{tabular}




\begin{tabular}{|c|c|c|}
\hline \multicolumn{3}{|c|}{ Postura Estratégica para a Inovação Sustentável } \\
\hline Empresa & Variáveis & Evidências \\
\hline \multirow{2}{*}{ Gama } & $\begin{array}{l}\text { Inovação } \\
\text { em produto, } \\
\text { processo e } \\
\text { incremental }\end{array}$ & $\begin{array}{l}\text { "Inovamos tanto em produto como em processo. O grau de nossas } \\
\text { inovações é sobretudo incremental." }\end{array}$ \\
\hline & $\begin{array}{l}\text { Nível de } \\
\text { sustenta- } \\
\text { bilidade } \\
\text { proativa }\end{array}$ & $\begin{array}{l}\text { "A questão de sermos inovadores envolve todas as realidades, } \\
\text { social, ambiental, econômica. Então, quando a empresa nasceu já } \\
\text { consideramos essas questões na construção do prédio, e buscamos } \\
\text { soluções sustentáveis nos produtos que desenvolvemos." }\end{array}$ \\
\hline \multirow{5}{*}{ Delta } & $\begin{array}{l}\text { Inovação } \\
\text { em produto } \\
\text { e processo }\end{array}$ & $\begin{array}{l}\text { "Inovamos em produto e em processo. Temos tentado levar coisas } \\
\text { novas, que sejam necessárias e úteis para as pessoas, não traba- } \\
\text { lhamos em um mercado onde a inovação tem que ser diária, e } \\
\text { sim com produtos necessários, muita coisa que tínhamos que é } \\
\text { desnecessário, cortamos. A acessibilidade ao produto também é } \\
\text { um desafio da sustentabilidade, não é só ter produto bom, é ter } \\
\text { produto que todas as pessoas consigam acessar em termos físicos e } \\
\text { pagar por ele." }\end{array}$ \\
\hline & $\begin{array}{l}\text { Grau incre- } \\
\text { mental de } \\
\text { novidade } \\
\text { em produto }\end{array}$ & $\begin{array}{l}\text { "É mais incremental do que radical. Em produtos temos muitas } \\
\text { inovações incrementais, ganhos pequenos incrementais em várias } \\
\text { linhas de produtos, que as vezes até são meio imperceptíveis, mas } \\
\text { no fundo, olhando para as questões socioambientais são melhorias } \\
\text { bem interessantes." }\end{array}$ \\
\hline & $\begin{array}{l}\text { Grau } \\
\text { radical de } \\
\text { novidade } \\
\text { na gestão }\end{array}$ & $\begin{array}{l}\text { "Radical é mais na gestão, no modelo de negócio, no jeito de fazer } \\
\text { as coisas, o trabalho muito mais coletivo do que individual, muito } \\
\text { mais cooperativo do que competitivo, esse trabalho de decisões } \\
\text { importantes mais demoradas, de mais discussão, é um pouquinho } \\
\text { mais radical." }\end{array}$ \\
\hline & $\begin{array}{l}\text { Nível de } \\
\text { sustenta- } \\
\text { bilidade } \\
\text { proativa }\end{array}$ & $\begin{array}{l}\text { "É proativa porque fazemos muitas coisas bem diferentes, bem } \\
\text { mais caras, bem mais demoradas, procuramos fazer coisas inova- } \\
\text { doras, não porque queremos, para fazer marketing, para bonito, } \\
\text { para ganhar mais dinheiro. É porque achamos que é preciso mudar } \\
\text { muitas coisas no mundo dos negócios e para as pessoas." }\end{array}$ \\
\hline & $\begin{array}{l}\text { Novo dire- } \\
\text { cionamento } \\
\text { estratégico, } \\
\text { a partir de } \\
2009\end{array}$ & $\begin{array}{l}\text { "Uma série de direcionamentos, que são grandes decisões estraté- } \\
\text { gicas que a empresa tomou, a partir de } 2009 \text {, e tem uma série de } \\
\text { inovações necessárias, para que consigamos fazer jus a ele. Mas } \\
\text { de onde veio tudo? Não é assim do nada, temos uma parceria } \\
\text { com uma consultoria de São Paulo que nos ajuda em planejamen- } \\
\text { to estratégico sustentável, e nos baseamos em referências globais } \\
\text { como o GRI, Instituto Ethos, Pacto Global, ISO 26000. Isso é só } \\
\text { orientação, ninguém está obrigando a fazer nada, nem o cliente, } \\
\text { nenhuma lei." }\end{array}$ \\
\hline
\end{tabular}

A partir dos dados apresentados, percebe-se que a empresa Alfa inova principalmente em produto, processo e de forma incremental, de modo que as suas inovações em processo estão orientadas para a introdução de novos produtos. Na visão do entrevistado, a 
empresa está constantemente melhorando os seus produtos a fim de acompanhar as tendências do mercado e superar a concorrência. Em relação ao nível de sustentabilidade, a postura da Alfa é proativa, tendo em vista que, em alguns casos, as políticas estabelecidas pela companhia são mais restritivas do que a legislação brasileira, pois englobam regras adotadas também em outros países, como restrições a algumas classes de produtos químicos em decorrência de preocupações ambientais.

A empresa Alfa também possui cargos ligados à sustentabilidade no seu board executivo global e uma governança estratégica dedicada à discussão e implementação do plano de sustentabilidade, formada pela presidência e pelas diretorias de $P \& D$, do instituto, de marketing, de recursos humanos e de operações industriais.

$\mathrm{Na}$ empresa Beta, ficou evidenciado que a inovação ocorre em produto e em processo, prioritariamente de forma incremental. A organização possui uma postura proativa quanto à sustentabilidade, tendo em vista que avalia periodicamente, por meio de uma matriz de materialidade, alguns temas a fim de embasar a sua estratégia de contribuição ao desenvolvimento sustentável. Em 2013, essa avaliação foi renovada com base em um processo estruturado de consulta às partes interessadas. A matriz partiu dos aspectos de sustentabilidade da Global Reporting Initiative e chegou a 29 aspectos a serem avaliados. Destes aspectos, 17 foram considerados materiais, por serem de alta criticidade. E estes, por sua vez, foram consolidados em dez macro-objetivos estratégicos para a contribuição da empresa ao desenvolvimento sustentável.

Os dez macro-objetivos relacionam-se, transversalmente, com os três pilares da estratégia de sustentabilidade: 1) processos e recursos cada vez mais sustentáveis; 2) portfólio de produtos cada vez mais sustentável; e 3) soluções para que a sociedade tenha uma vida cada vez mais sustentável. Para cada macro-objetivo, foram definidas metas estratégicas para o ano de 2020, assim como ações intermediárias a fim de alcançá-los. Os dez macro-objetivos são segurança, resultados econômico-financeiros, pós-consumo, recursos renováveis, eficiência hídrica, mudanças climáticas, eficiência energética, desenvolvimento local, desenvolvimento de soluções, fortalecimento das práticas. 
Em relação à empresa Gama, a inovação ocorre em produto e processo, de forma incremental, uma vez que a organização busca constantemente desenvolver soluções adequadas às necessidades dos clientes. Na visão da entrevistada, a Gama possui um nível proativo de sustentabilidade tendo em vista que o seu parque tecnológico foi construído visando a uma melhor utilização dos recursos naturais, e a organização busca o desenvolvimento de soluções sustentáveis para os clientes.

No que se refere à empresa Delta, foi possível constatar que a inovação ocorre em produto e processo, de modo que há uma busca por melhorias em seus produtos visando oferecer algo útil e acessível aos clientes do ponto de vista físico e financeiro. Na visão do entrevistado, a organização cortou, da sua linha de produtos, itens considerados desnecessários para os consumidores. Na empresa, a inovação em produto ocorre de forma mais incremental, tendo em vista que foram introduzidas pequenas melhorias em prol da sustentabilidade, como a substituição de embalagem plástica por papel, redução do tamanho da embalagem para transportar mais produtos poluindo menos, substituição de matérias-primas não renováveis por renováveis.

Contudo, o entrevistado ressalta que, na gestão, a empresa passou por uma mudança radical nos últimos anos a fim de atender às premissas do desenvolvimento sustentável, o que denota uma postura proativa. A empresa Delta assumiu, a partir do ano de 2009, um novo posicionamento estratégico, inserindo critérios econômicos, sociais e ambientais em seu compromisso institucional, unindo pessoas e organizações, zelando sempre pelo bem-estar. De modo que, visando atender a tais premissas, muitas inovações foram requeridas, sendo necessário fazer muitas coisas de forma diferente.

A partir do exposto, de modo geral, percebe-se que todas as empresas brasileiras entrevistadas inovam em produto e em processo. O grau de novidade dos novos produtos e/ou processos caracteriza-se, em sua maioria, como incremental, por meio da constante busca pela melhoria contínua a fim de atender às demandas de um mercado cada vez mais exigente. Apenas na empresa Delta foi possível vislumbrar que ocorreu uma inovação radical na gestão a partir de 2009, quando a organização aderiu a um novo posicionamento 
estratégico em prol do desenvolvimento sustentável, passando a se preocupar mais com o bem-estar das pessoas, do meio ambiente e da sociedade e não exclusivamente com o lucro. Em relação ao nível de sustentabilidade, foi possível constatar que todas as empresas possuem práticas proativas que vão além da conformidade legal.

Os resultados corroboram a visão de Szekely e Strebel (2012), ao destacarem que o desenvolvimento de novos produtos, serviços e processos internos integrando aspectos ambientais, sociais e econômicos tem ocorrido em grande parte de forma incremental.

Contudo, foi possível verificar que as empresas brasileiras entrevistadas encontram-se em um estágio evolutivo mais avançado em relação à estratégia para inovação sustentável, tendo como base os cinco estágios propostos por Nidumolu, Prahalad e Rangaswani (2009), que destacam que as empresas, em um primeiro momento, visam atender aos aspectos legais, passando pelo envolvimento da stakeholders, pelo desenvolvimento de novos produtos e serviços e de novos modelos de negócios, até alcançar o estágio mais complexo, que se refere à criação de práticas de última geração.

Desse modo, foi possível perceber que as empresas brasileiras objeto do estudo possuem estratégias proativas no que tange à sustentabilidade, uma vez que desenvolvem ações que não estão focadas somente no atendimento da legislação, considerando a visão de Aragón-Correa et al. (2008) ao colocar que as estratégias reativas apenas visam ao atendimento dos requisitos legais, enquanto que as estratégias proativas incluem práticas ecoeficientes voluntárias.

As principais evidências encontradas no que se refere às práticas de inovação sustentável serão apresentadas a seguir, considerando as seguintes categorias de análise: adaptação dos negócios para a sociedade; desenvolvimento de soluções sustentáveis; maximização da eficiência energética, hídrica e redução das emissões; criação de valor a partir do desperdício; substituição por processos renováveis e naturais; entrega de funcionalidade ao invés de propriedade e adoção de papel de liderança.

O Quadro 4 resume as principais evidências encontradas no que se refere à adaptação dos negócios para a sociedade. 


\section{Quadro 4 - Adaptação dos negócios para a sociedadelmeio ambiente}

\begin{tabular}{|c|c|c|}
\hline \multicolumn{3}{|r|}{ Adaptação dos negócios para a sociedade } \\
\hline Empresa & Variáveis & Evidências \\
\hline \multirow[t]{2}{*}{ Alfa } & $\begin{array}{l}\text { Mecanismos de } \\
\text { interação com } \\
\text { stakeholders }\end{array}$ & $\begin{array}{l}\text { "Temos o Centro de Relacionamento com o Cliente para o aten- } \\
\text { dimento dos canais de venda e dos clientes diretos corporativos; } \\
\text { e o Fale com para atender as necessidades dos consumidores, } \\
\text { usuários de produtos e serviços, pelos canais telefone, e-mail } \\
\text { e chat. Para os colaboradores temos pesquisa de opinião, blog } \\
\text { do diretor-presidente, ouvidoria, reuniões trimestrais com a } \\
\text { diretoria, intranet. Temos um relacionamento estreito com os } \\
\text { fornecedores." }\end{array}$ \\
\hline & $\begin{array}{l}\text { Mecanismo de } \\
\text { interação com a } \\
\text { comunidade }\end{array}$ & $\begin{array}{l}\text { O relacionamento com a comunidade é conduzido principal- } \\
\text { mente por meio do nosso Instituto, que existe desde 2006, ele } \\
\text { derivou de um forte grupo de voluntários que a empresa tinha } \\
\text { desde } 1978 \text { e tem quatro pilares de atuação: Ciência tecnologia, } \\
\text { Educacão, Tecnologia Social e Desenvolvimento Social." }\end{array}$ \\
\hline Beta & $\begin{array}{l}\text { Mecanismos de } \\
\text { interação com } \\
\text { os stakeholders }\end{array}$ & $\begin{array}{l}\text { "Temos diversos mecanismos de interação com os stakeholders, } \\
\text { como reuniões, pesquisa de reputação, participação em feiras do } \\
\text { setor, participações em reuniões setoriais, press releases, entrevis- } \\
\text { tas, projetos em parceria, e-mails, site, relatórios, teleconferência } \\
\text { de resultados, campanhas internas, informativos, diálogos de } \\
\text { segurança, prêmio destaque, intranet, pesquisas de clima e } \\
\text { sobre comunicação, projetos, relacionamentos com os repre- } \\
\text { sentantes locais, visitas às instalações, eventos, feiras do setor, } \\
\text { patrocínios, canal pela internet, atendimento comercial por } \\
\text { gerentes de conta, agenda de desenvolvimento técnico." }\end{array}$ \\
\hline Gama & $\begin{array}{l}\text { Mecanismos de } \\
\text { interação com } \\
\text { os stakeholders }\end{array}$ & $\begin{array}{l}\text { Interagimos por meio do website; palestras e bate-papo dos di- } \\
\text { retores com os colaboradores; redes sociais, informativo mensal; } \\
\text { LCDs que divulgam mensagens e campanhas de comunicação; } \\
\text { sistema de gerenciamento de ideias; café com o presidente; vi- } \\
\text { sitas, reuniões, e-mails, telefonemas; apresentações, catálogos, e } \\
\text { propostas comerciais customizadas; divulgação de cases de su- } \\
\text { cesso e depoimentos de clientes; divulgação de releases para a } \\
\text { imprensa, encontro com os distribuidores na sede da empresa." }\end{array}$ \\
\hline \multirow{3}{*}{ Delta } & $\begin{array}{l}\text { Priorização de } \\
\text { fornecedores } \\
\text { locais }\end{array}$ & $\begin{array}{l}\text { "Temos um indicador que se chama "Compras Locais", quanto } \\
\text { mais conseguirmos adquirir produtos e serviços necessários } \\
\text { para a operação localmente, melhor." }\end{array}$ \\
\hline & $\begin{array}{l}\text { Mecanismos de } \\
\text { interação com } \\
\text { os stakeholders }\end{array}$ & $\begin{array}{l}\text { "O nosso mecanismo basicamente é relacionamento, que é } \\
\text { aquela postura nova, muito diferente do passado de conversar } \\
\text { com as pessoas, de unir pessoas e organizações, vamos muito } \\
\text { ao encontro das pessoas, nas empresas promovemos encontros, } \\
\text { reuniões, conversas com professores, com alunos, com deficien- } \\
\text { tes, com as empresas locais para buscar soluções [...] O melhor } \\
\text { mecanismo para fazer sustentabilidade é a conversa, é o diálo- } \\
\text { go, é o relacionamento. Não tem uma ferramenta... [...]." }\end{array}$ \\
\hline & $\begin{array}{l}\text { Necessidade de } \\
\text { compreensão } \\
\text { da nova lógica } \\
\text { da sustentabi- } \\
\text { lidade pelos } \\
\text { stakeholders }\end{array}$ & $\begin{array}{l}\text { complexos, que os parceiros têm que compreender. A susten- } \\
\text { tabilidade de forma geral é uma coisa muito nova, demora até } \\
\text { que as empresas acreditem e vejam que realmente é uma coisa } \\
\text { positiva, que não é só o lucro que é necessário. Temos desafios, } \\
\text { coisas que temos feito há anos, que recentemente se concretiza- } \\
\text { ram..." }\end{array}$ \\
\hline
\end{tabular}


A empresa Alfa possui grande integração com os seus stakeholders, tendo em vista que considera fundamental o relacionamento com os seus públicos de interesse, buscando entender as suas necessidades e desenvolver ações conjuntas da melhor maneira possível. A empresa conta com diversos mecanismos para interação com os clientes, os fornecedores, os colaboradores, a comunidade local e o governo. Destaca-se que a organização possui um Instituto que consiste no seu principal mecanismo de interação com a comunidade, por meio do qual desenvolve uma série de ações sociais, visando difundir o empreendedorismo para as futuras gerações com base nas suas áreas de atuação, em ciência e tecnologia.

A empresa Beta também apresenta forte atuação junto aos stakeholders, utilizando diferentes formas e meios para interagir com seus públicos de relacionamento, a fim de manter comunicação ágil e transparente. A organização realiza anualmente um mapeamento das partes interessadas relevantes, no qual são definidos como prioritários os públicos que se conectam diretamente com as suas operações. As ações de engajamento são realizadas em nível corporativo, tanto por meio das consultas de sustentabilidade e da pesquisa de reputação, realizada anualmente desde 2009 com representantes de todas as áreas a fim de discutir os principais riscos e oportunidades no processo de fortalecimento da confiança dos públicos de relacionamento da empresa, quanto pelas diversas equipes responsáveis pelos relacionamentos com os grupos de interesse, em reuniões e negociações.

A empresa Gama promove a integração com as comunidades locais para a geração de benefícios sociais e ambientais por meio de diversas ações, como o incentivo a projetos e promoção de eventos ligados a empreendedorismo e inovação, doações a instituições sociais, e também conta com diversos mecanismos de interação com os stakeholders, o que corrobora com a sua visão de ser referência em tecnologia por muitas gerações, sendo aberta, inclusiva, preservando o meio ambiente, trazendo benefícios para a comunidade e para o mundo.

A empresa Delta possui grande integração com as comunidades locais, pois participa de eventos na cidade, apoia iniciativas locais, participando de projetos junto a entidades como a Cooperativa de 
Catadores, Santa Cruz Novos Rumos, Produtores de Alimentos Orgânicos. Além disso, a empresa possui um indicador que visa substituir as importações e valorizar a compra local de produtos e serviços necessários para a operação, por meio do estabelecimento de critérios de seleção e procedimentos de compra com prioridade para fornecedores locais. O entrevistado destaca que o principal mecanismo de interação com as partes interessadas é o relacionamento por intermédio do diálogo, visando à busca por melhores soluções do ponto de vista econômico, social e ambiental. Ainda, na sua visão, faz-se necessário que as partes interessadas compreendam melhor a nova lógica da sustentabilidade, tendo em vista que se trata de algo novo e requer tempo para que os stakeholders acreditem e a vislumbrem de forma positiva.

De modo geral, as empresas entrevistadas têm vários mecanismos de interação com os stakeholders e se relacionam ativamente com as comunidades locais. Pode-se destacar que a empresa Alfa possui um Instituto que consiste no seu principal mecanismo de relacionamento com a comunidade e que centraliza as ações sociais da organização. Por sua vez, a empresa Delta busca priorizar as compras de fornecedores locais e reconhece a necessidade de uma melhor compreensão da sustentabilidade como algo positivo pelos stakeholders.

Os achados da pesquisa vão ao encontro da visão de Ayuso et al. (2011), que destacam a necessidade de as empresas inovarem, reinventando a maneira como se relacionam com os seus múltiplos atores, de modo que tais relações podem ser uma importante fonte de ideias para inovações.

O Quadro 5 resume as principais evidências no que tange ao desenvolvimento de soluções sustentáveis. 


\section{Quadro 5 - Desenvolvimento de soluções sustentáveis}

\begin{tabular}{|c|c|c|}
\hline \multicolumn{3}{|c|}{ Desenvolvimento de soluções sustentáveis } \\
\hline Empresa & Variáveis & Evidências \\
\hline \multirow{3}{*}{ Alfa } & $\begin{array}{l}\text { Soluções sus- } \\
\text { tentáveis em } \\
\text { processos }\end{array}$ & $\begin{array}{l}\text { "Ainda na década de 70, lançamos o programa "Prevenção à Polui- } \\
\text { ção se Paga", que se tornou referência para outras empresas e visa } \\
\text { disseminar a cultura da prevenção à poluição, ao invés de investir } \\
\text { em sistemas de controle, aliada ao ganho financeiro por meio de } \\
\text { soluções práticas e eficientes para a proteção do meio ambiente, pro- } \\
\text { porcionando benefícios à empresa, aos clientes e aos fornecedores." }\end{array}$ \\
\hline & $\begin{array}{l}\text { Parcerias } \\
\text { em prol da } \\
\text { sustentabili- } \\
\text { dade }\end{array}$ & $\begin{array}{l}\text { "Temos uma iniciativa que mobiliza os consumidores para a reci- } \\
\text { clagem de esponjas e que, em parceria com a TerraCycle, recolhe e } \\
\text { recicla os produtos e as embalagens pós-consumo." }\end{array}$ \\
\hline & $\begin{array}{l}\text { Soluções sus- } \\
\text { tentáveis em } \\
\text { produtos }\end{array}$ & $\begin{array}{l}\text { "A empresa gerencia o ciclo de vida de cada produto com o objeti- } \\
\text { vo de analisar riscos e oportunidades de melhoria no que tange a } \\
\text { critérios ambientais, de saúde, segurança e sociais, desde a aquisi- } \\
\text { ção de matérias-primas, processo de manufatura, uso e aplicação } \\
\text { do produto até a disposição final." }\end{array}$ \\
\hline \multirow[b]{2}{*}{ Beta } & $\begin{array}{l}\text { Soluções sus- } \\
\text { tentáveis em } \\
\text { processos }\end{array}$ & $\begin{array}{l}\text { "Desenvolvemos a ferramenta SIGA para quantificar ganhos } \\
\text { ambientais de projetos de investimentos em instalações existentes, } \\
\text { como forma de garantir a melhoria do desempenho ambiental a par- } \\
\text { tir da conclusão do projeto. Também temos uma metodologia para } \\
\text { priorizar o portfólio de investimento do ano considerando critérios } \\
\text { de sustentabilidade estabelecidos pela matriz de materialidade." }\end{array}$ \\
\hline & $\begin{array}{l}\text { Soluções sus- } \\
\text { tentáveis em } \\
\text { produtos }\end{array}$ & $\begin{array}{l}\text { "Utilizamos a metodologia de Avaliação de Ciclo de Vida para } \\
\text { analisar os impactos ambientais (e, em alguns casos, sociais) po- } \\
\text { tenciais desde a extração da matéria-prima até a destinação final, o } \\
\text { que permite verificar qual alternativa é mais sustentável e melhor } \\
\text { embasa as decisões de negócio. Em 2010, colocamos no mercado o } \\
\text { polietileno verde, fabricado com matéria-prima renovável, o etanol } \\
\text { da cana-de-açúcar, que dá origem a produtos de 'plástico verde'. } \\
\text { Temos uma linha de resinas com desempenho diferenciado em } \\
\text { suas respectivas aplicações." }\end{array}$ \\
\hline Gama & $\begin{array}{l}\text { Soluções } \\
\text { sustentáveis } \\
\text { em processos } \\
\text { e produtos } \\
\end{array}$ & $\begin{array}{l}\text { "Quando a empresa nasceu já consideramos a sustentabilidade na } \\
\text { construção do prédio, e também nos projetos que desenvolvemos } \\
\text { com a comunidade, com o meio ambiente, e a busca por soluções } \\
\text { sustentáveis nos nossos produtos." }\end{array}$ \\
\hline \multirow{2}{*}{ Delta } & $\begin{array}{l}\text { Soluções sus- } \\
\text { tentáveis em } \\
\text { processos }\end{array}$ & $\begin{array}{l}\text { "Inauguramos recentemente um espaço chamado LABI, que é um } \\
\text { laboratório de inovação social, disponibilizado para a comunida- } \\
\text { de discutir sobre diversos assuntos. Reduzimos drasticamente as } \\
\text { emissões de gases do efeito estufa, através de várias melhorias. } \\
\text { Investimentos em estação de tratamento de efluentes, de tratamen- } \\
\text { to da água, redução da carga horária de trabalho de } 44 \mathrm{~h} \text { para } 40 \mathrm{~h} \\
\text { semanais, porque priorizamos o bem-estar das pessoas." }\end{array}$ \\
\hline & $\begin{array}{l}\text { Eliminação } \\
\text { dos produtos } \\
\text { licenciados } \\
\text { do portfólio }\end{array}$ & $\begin{array}{l}\text { "Uma decisão importante que a empresa tomou em 2010, foi elimi- } \\
\text { nar do seu portfólio, produtos licenciados, com uma rentabilidade } \\
\text { bastante alta para a empresa, que davam um ótimo retorno finan- } \\
\text { ceiro, e que têm um preço muito mais alto para o consumidor, e } \\
\text { considerando que um problema grave do Brasil é a educação, e a } \\
\text { empresa atua nesse ramo, chegamos à conclusão que mais atrapa- } \\
\text { lhávamos a população do que ajudávamos com esses produtos." }\end{array}$ \\
\hline
\end{tabular}


A empresa Alfa foi pioneira na década de 1970 ao introduzir o programa 3P - Prevenção à Poluição se Paga, que se tornou referência para outras organizações e tem como objetivo evitar custos com a má gestão dos processos e estimular o uso dos materiais aliados à prevenção à poluição. Segundo o relatório de sustentabilidade da empresa, o programa contabilizou no Brasil, desde 2001, 427 projetos que evitaram mais de 19,4 mil toneladas de poluição, propiciando uma economia de mais de 37,4 milhões de dólares.

Ainda foi possível observar que a organização realiza o gerenciamento do ciclo de vida dos produtos (Life Cycle Management - LCM), visando identificar pontos críticos nos aspectos de meio ambiente, saúde e segurança (Environmental, Health and Safety - EHS), voltado à gestão eficiente de recursos e energia ao longo de todo o ciclo de vida de um produto, ou seja, desde o projeto, desenvolvimento, manufatura, utilização, até a disposição final. A Alfa possui uma iniciativa pioneira que mobiliza os consumidores para a reciclagem de esponjas de cozinha e, além disso, a sua estratégia de crescimento contempla uma série de soluções com vantagens ambientais e energéticas.

Na empresa Beta, o compromisso com o desenvolvimento sustentável permeia a sua estratégia e atuação, estando aliado à inovação. A organização visa ao desenvolvimento de soluções sustentáveis em processos e produtos, com o objetivo de difundir o plástico como solução para o desenvolvimento sustentável, em virtude do seu potencial para melhorar a vida das pessoas. A Beta possui uma ferramenta para quantificar os ganhos ambientais de projetos de investimentos em instalações existentes, visando garantir a melhoria do desempenho ambiental. Também desenvolveu uma metodologia para priorizar investimentos considerando os critérios de sustentabilidade estabelecidos pela sua matriz de materialidade. A organização adota a ferramenta de Avaliação de Ciclo de Vida (ACV) desde o ano de 2005, com o objetivo de analisar os impactos socioambientais potenciais ao longo da vida de um produto, desde a extração da matéria-prima até a destinação final. Segundo o relatório de sustentabilidade da empresa, em 2014 foram desenvolvidos 58 estudos de ACV, vinte a mais do que em 2013.

A empresa também busca o reconhecimento como líder na fabricação de produtos químicos e resinas termoplásticas a partir 
de matérias-primas renováveis, tendo desenvolvido o polietileno verde, que consiste em um tipo de biopolímero, originado da cana-de-açúcar, matéria-prima de fonte renovável, que pode ser reciclado no final de sua vida na mesma cadeia do polietileno tradicional, sem causar contaminação. Para obter tal reconhecimento, a empresa investe em pesquisa e tecnologia, a partir de acordos de cooperação tecnológica e parcerias com clientes, visando consolidar o Brasil como país estratégico na agenda da química renovável, por meio de tecnologias que viabilizem o consumo de matérias-primas de fonte renovável e seus derivados.

Na visão da entrevistada da empresa Gama, a sustentabilidade nasce com a inovação, de modo que a busca de soluções sustentáveis por meio da inserção da variável socioambiental ocorre desde a construção do parque tecnológico até o desenvolvimento de produtos que contemplam a preocupação com a economia de recursos.

A empresa Delta possui ações diferenciadas relacionadas ao seu novo posicionamento estratégico visando cumprir o seu compromisso institucional de unir pessoas e organizações para criar soluções sustentáveis. Nesse sentido, a organização tem investido em práticas para a redução das emissões de gases de efeito estufa, para o bem-estar dos colaboradores e para a promoção da inovação social.

Aliado ao seu novo posicionamento, a Delta eliminou do seu portfólio os produtos licenciados, por terem um custo mais alto para o consumidor e não estarem contribuindo para a educação. Nessa ação, é possível perceber que a empresa abdicou de um produto que tinha uma alta lucratividade em prol de um benefício social.

Em geral, os resultados constataram que as organizações analisadas possuem soluções sustentáveis que estão relacionadas ao desenvolvimento de novos produtos e/ou processos, o que corrobora a visão de Nidumolu, Prahalad e Rangaswani (2009), ao defenderem a necessidade de a sustentabilidade ser vislumbrada como uma fronteira da inovação.

Além disso, pode-se observar que as empresas analisadas estão desenvolvendo soluções sustentáveis para maximizar os benefícios para a sociedade e o meio ambiente, conforme destacado por Bocken et al. (2014). 


\section{O Quadro 6 resume as principais evidências relacionadas à ma- ximização da eficiência energética, hídrica e redução das emissões.}

\section{Quadro 6 - Maximização da eficiência energética e material}

\begin{tabular}{|c|c|c|}
\hline Empresa & Variáveis & Evidências \\
\hline \multirow{3}{*}{ Alfa } & $\begin{array}{l}\text { Eficiência } \\
\text { energética }\end{array}$ & $\begin{array}{l}\text { "Realizamos ao longo dos últimos dois anos o Projeto de Eficiência } \\
\text { Energética, que busca uma gestão constante, a fim de mapear o uso } \\
\text { da energia e possíveis melhorias." }\end{array}$ \\
\hline & $\begin{array}{l}\text { Redução das } \\
\text { emissões }\end{array}$ & $\begin{array}{l}\text { "Um importante instrumento para a redução das emissões é o 3P } \\
\text { (Prevenção à Poluição se Paga). Temos rigoroso controle sobre a } \\
\text { emissão de gases refrigerantes, renovamos a quase totalidade da } \\
\text { frota de veículos a cada } 36 \text { meses, executamos plano de manu- } \\
\text { tenção preventiva nos equipamentos e veículos, enviamos comu- } \\
\text { nicação mensal indicando a viabilidade de uso do etanol para os } \\
\text { motoristas, acompanhamos os abastecimentos junto ao fornecedor, } \\
\text { analisamos o TCO (Total Cost of Ownership - Custo total de posse } \\
\text { do veículo por quilômetro). Temos uma política global que prevê a } \\
\text { obrigatoriedade de aprovação de todos os deslocamentos nacionais } \\
\text { e internacionais. Iniciamos o trabalho de neutralização das emis- } \\
\text { sões do CTC (Centro Técnico para Clientes), por meio da compra } \\
\text { de créditos de carbono social de uma cerâmica do Amazonas, que } \\
\text { reverte o investimento em melhorias no ambiente de trabalho e } \\
\text { ações com a comunidade." }\end{array}$ \\
\hline & $\begin{array}{l}\text { Geren- } \\
\text { ciamento } \\
\text { de água e } \\
\text { efluentes }\end{array}$ & $\begin{array}{l}\text { "Utilizamos água proveniente de poços artesianos, lago superficial } \\
\text { e pequena parte de fornecimento externo por companhia de sane- } \\
\text { amento. Em todas as unidades o gerenciamento da água respeita } \\
\text { normas e padrões da legislação pertinente. Há em operação siste- } \\
\text { mas de Osmose Reversa e Ozônio que permitem reutilizar } 24 \text { mil } \\
\text { metros cúbicos de água por ano, o equivalente a } 36 \% \text { do volume de } \\
\text { água utilizada." }\end{array}$ \\
\hline
\end{tabular}




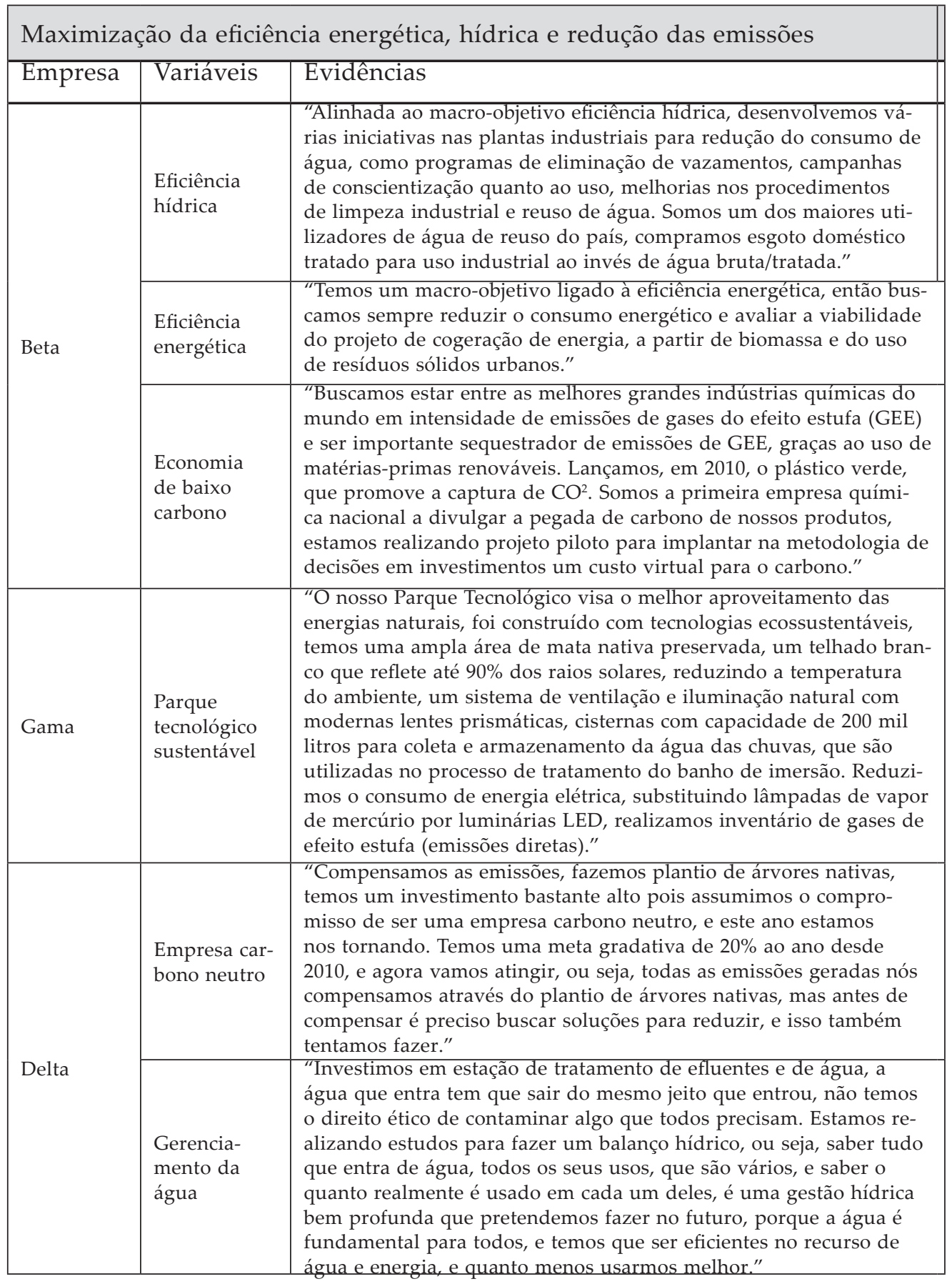


Maximização da eficiência energética, hídrica e redução das emissões

\begin{tabular}{|l|l|l|}
\hline Empresa & Variáveis & Evidências \\
\hline & & $\begin{array}{l}\text { "Entramos no mercado livre de energia no ano retrasado, que é } \\
\text { um mercado onde a energia é limpa, isso é fundamental no nosso } \\
\text { posicionamento, só que tem um detalhe, essa energia é bem mais } \\
\text { cara. Então pagamos mais caro pela energia do que o convencional, } \\
\text { chamado mercado cativo. Usamos uma energia limpa, de fontes } \\
\text { limpas, a um custo superior. Temos alguns estudos e projetos, } \\
\text { para utilizar energia interna oriunda de energia solar, chamada de } \\
\text { energia fotovoltaica. Estamos estudando para conseguir, de repente, } \\
\text { ter essa energia disponível para a operação e o excedente é possível } \\
\text { vender e colocar na rede elétrica." }\end{array}$ \\
\hline
\end{tabular}

A empresa Alfa busca, de forma sistemática, a maximização da eficiência energética, mapeando o uso de energia e adotando possíveis melhorias. No que tange às emissões, a organização possui uma metodologia de balanceamento de gases de efeito estufa, procurando reduzir as emissões geradas no transporte de produtos e pessoas, por meio de ações como política de controle de viagens nacionais e internacionais, manutenção preventiva nas máquinas e equipamentos, monitoramento dos transportes, compra de créditos de carbono, entre outras. Em 2014, a Alfa registrou uma redução de 23\% das emissões de Gases de Efeito Estufa - GEE em relação ao ano de 2013. A empresa também busca a eficiência hídrica por meio da utilização de água proveniente de poços artesianos, lago superficial e sistemas de reuso de água.

A empresa Beta possui macro-objetivos relacionados à eficiência energética, hídrica e a mudanças climáticas, desse modo tem ações alinhadas a eles. A companhia teve, em 2014, uma economia estimada de R \$ 1,9 milhão, devido a melhorias no consumo e descarte de água, e uma redução acumulada de $10 \%$ no consumo de energia por tonelada produzida entre 2002 e 2014. Além disso, a empresa, em consonância com as políticas governamentais e as iniciativas voluntárias para uma economia de baixo carbono, desenvolve suas atividades visando à mitigação e à adaptação às mudanças climáticas, investindo em produtos com matérias-primas renováveis e projetos relacionados a créditos de carbono. Ainda na visão da empresa, o plástico, por suas características de leveza e resistência, 
Gestão estratégica da inovação sustentável:

UM ESTUDO DE CASO EM EMPRESAS INDUSTRIAIS BRASILEIRAS 
tem contribuído para a redução do consumo de combustíveis fósseis e, por conseguinte, para a redução das emissões de gases de efeito estufa por meio de soluções para reduzir o peso das embalagens e dos veículos automotores.

O Parque Tecnológico da empresa Gama foi construído com tecnologias sustentáveis, permitindo economia de energia e de água, uma vez que conta com um telhado branco que reflete até $90 \%$ dos raios solares, reduzindo a temperatura do ambiente, um sistema de ventilação e iluminação natural com modernas lentes prismáticas e um sistema para a coleta e o armazenamento da água das chuvas. A empresa realiza também inventário de gases de efeito estufa relativo às emissões diretas.

A empresa Delta compensa as emissões de gases de efeito estufa por meio do plantio de árvores nativas, possui políticas para a sua redução, tais como substituição da caldeira a óleo, redução das viagens aéreas, utilização de transporte por navio e trem. A organização também conta com ações para o gerenciamento da água, com investimentos em tratamento de água e efluentes e faz parte do mercado livre de energia, a fim de utilizar energia de fontes limpas. No que tange à eficiência hídrica e energética, constatou-se que a empresa está realizando estudos a fim de promover a melhoria nesses aspectos.

Os resultados permitiram observar que as empresas Alfa, Beta e Delta possuem políticas específicas relacionadas à maximização da eficiência energética, hídrica e redução das emissões. No que se refere à empresa Gama, foi possível observar que as ações são mais pontuais e prioritariamente relacionadas ao parque tecnológico da organização. Em geral, as empresas entrevistadas estão cumprindo um dos estágios da estratégia de inovação sustentável defendido por Nidumolu, Prahalad e Rangaswani (2009), de que as empresas devem aumentar a eficiência em toda a sua cadeia de valor.

O Quadro 7 resume as principais evidências referentes à criação de valor a partir do desperdício. 


\section{Quadro 7-Criação de valor a partir do desperdício}

\begin{tabular}{|c|c|c|}
\hline \multicolumn{3}{|c|}{ Criação de valor a partir do desperdício } \\
\hline Empresa & Variáveis & Evidências \\
\hline \multirow{2}{*}{ Alfa } & $\begin{array}{l}\text { Gerenciamento } \\
\text { de resíduos }\end{array}$ & $\begin{array}{l}\text { "Temos uma campanha denominada Custo da Má Qualidade } \\
\text { para difundir entre os funcionários a consciência da redução da } \\
\text { geração de resíduos, um programa desde } 2009 \text { em parceria com } \\
\text { associações que fazem a identificação, a capacitação e a instru- } \\
\text { mentalização de cooperativas para contribuir com a reciclagem } \\
\text { pós-consumo." }\end{array}$ \\
\hline & $\begin{array}{l}\text { Sustentabilidade } \\
\text { na cadeia de } \\
\text { valor }\end{array}$ & $\begin{array}{l}\text { "Utilizamos a metodologia Lean Six Sigma a fim de melhorar } \\
\text { a produtividade e reduzir as operações nas fábricas, a partir } \\
\text { de modificações de layout. Temos uma área responsável pelo } \\
\text { estudo do ciclo de vida dos produtos desde a aquisição da ma- } \\
\text { téria-prima até a disposição final. Usamos a ferramenta de LCM } \\
\text { (Life Cicle Management), adotada mundialmente." }\end{array}$ \\
\hline \multirow[b]{2}{*}{ Beta } & $\begin{array}{l}\text { Gerenciamento } \\
\text { de resíduos }\end{array}$ & $\begin{array}{l}\text { "A minimização e correta destinação de resíduos faz parte do } \\
\text { macro-objetivo de segurança, devido ao potencial impacto } \\
\text { negativo à saúde das pessoas e ao meio ambiente. A principal } \\
\text { destinação dada a resíduos perigosos é a incineração. Já para os } \\
\text { resíduos não perigosos, os principais envios são para recicla- } \\
\text { gem, aterro e injeção subterrânea." }\end{array}$ \\
\hline & $\begin{array}{l}\text { Sustentabilidade } \\
\text { na cadeia de } \\
\text { valor }\end{array}$ & $\begin{array}{l}\text { "Utilizamos a metodologia de Avaliação de Ciclo de Vida } \\
\text { (ACV) desde 2005, para melhor entender aos aspectos relativos } \\
\text { à sustentabilidade em sua cadeia de valor. Criamos a Rede } \\
\text { Empresarial Brasileira de ACV, fórum que congrega empresas, } \\
\text { por iniciativa voluntária, para discutir o conceito de ACV e dis- } \\
\text { seminar boas práticas na aplicação da ferramenta no ambiente } \\
\text { empresarial." }\end{array}$ \\
\hline \multirow{2}{*}{ Gama } & $\begin{array}{l}\text { Gerenciamento } \\
\text { dos resíduos }\end{array}$ & $\begin{array}{l}\text { "Temos um programa de resíduos recicláveis e destinação cor- } \\
\text { reta em sua totalidade dos resíduos classe I e II com a triagem, } \\
\text { separação e posterior comercialização com a receita aplicada em } \\
\text { fundo financeiro para os colaboradores. E algumas práticas de } \\
\text { reutilização de sobras de chapas de aço carbono cortadas e ou } \\
\text { vazadas para confeccionar peças menores." }\end{array}$ \\
\hline & $\begin{array}{l}\text { Alta durabilida- } \\
\text { de e manutenção } \\
\text { contínua }\end{array}$ & $\begin{array}{l}\text { "Desenvolvemos produtos com alta durabilidade, com vida } \\
\text { útil mais longa possível para não terem uma substituição tão } \\
\text { rápida. Também reformamos e remodelamos os produtos dos } \\
\text { clientes após anos de uso comercial e contínuo, como pistas de } \\
\text { boliche, oferecendo todo o suporte e a tecnologia." }\end{array}$ \\
\hline Delta & $\begin{array}{l}\text { Política de logís- } \\
\text { tica reversa e de } \\
\text { gerenciamento } \\
\text { de resíduos }\end{array}$ & $\begin{array}{l}\text { "Temos uma política de logística reversa atrelada à política } \\
\text { nacional de resíduos sólidos, que foi aprovada em } 2010 \text {. Os } \\
\text { resíduos de borracha todos são reaproveitados e temos desa- } \\
\text { fios enormes com relação a outros resíduos, principalmente } \\
\text { resíduos têxteis." }\end{array}$ \\
\hline
\end{tabular}


A empresa Alfa realiza o gerenciamento dos resíduos sólidos, possuindo programas específicos que visam sensibilizar os colaboradores para diminuir a geração de resíduos. A organização analisa todos os impactos ambientais dos seus produtos, desde a concepção até o descarte por meio da ferramenta LCM, e conta com a metodologia Six Sigma para a otimização dos seus processos.

A empresa Beta conta com uma política de gerenciamento de resíduos que resultou em uma economia de cerca de $\mathrm{R} \$ 53,7$ milhões em 2014. A organização realiza a avaliação do ciclo de vida para melhor entender a sustentabilidade em sua cadeia de valor e também teve a iniciativa de criação da Rede Empresarial Brasileira de ACV, que consiste em um fórum para a discussão e a disseminação de boas práticas na aplicação da ferramenta no ambiente empresarial.

A empresa Gama possui práticas para a reciclagem e o reaproveitamento de resíduos e conta com produtos de alta durabilidade que não têm rápida substituição.

A empresa Delta também conta com o gerenciamento de resíduos sólidos e uma política de logística reversa, de modo que alguns resíduos do processo produtivo, como os de borracha, são totalmente reaproveitados.

A partir dos resultados, é possível perceber que todas as empresas entrevistadas possuem políticas de gerenciamento de resíduos, buscando uma menor geração de resíduos e também práticas de reciclagem e reaproveitamento. De modo geral, os resultados da categoria de análise de criação de valor a partir do desperdício confirmam novamente as proposições de Nidumolu, Prahalad e Rangaswani (2009), ao colocarem que um dos estágios para a inovação sustentável envolve o aumento da eficiência em toda a cadeia de valor, incluindo a capacidade de a organização redesenhar as suas operações a fim de usar menos energia e água, produzir menos emissões e gerar menos resíduos.

No Quadro 8, é apresentado o resumo das principais evidências relacionadas à substituição por processos renováveis e naturais. 


\section{Quadro 8 - Substituição por processos renováveis e naturais}

\begin{tabular}{|c|c|c|}
\hline \multicolumn{3}{|c|}{ Substituição por processos renováveis e naturais } \\
\hline Empresa & Variáveis & Evidências \\
\hline Alfa & $\begin{array}{l}\text { Soluções com } \\
\text { recursos reno- } \\
\text { váveis }\end{array}$ & $\begin{array}{l}\text { "Temos uma busca constante por soluções que evitam } \\
\text { solventes orgânicos, compostos voláteis. Então, tem } \\
\text { esforço na operação e em tecnologia de produto para so- } \\
\text { luções sustentáveis. Comunicamos mensalmente sobre a } \\
\text { viabilidade de uso do etanol para os motoristas, ação que } \\
\text { aumenta o uso de combustível renovável em aproxima- } \\
\text { damente } 25 \% \text {." }\end{array}$ \\
\hline \multirow[b]{2}{*}{ Beta } & $\begin{array}{l}\text { Soluções com } \\
\text { recursos reno- } \\
\text { váveis }\end{array}$ & $\begin{array}{l}\text { "Um dos macro-objetivos da empresa está relacionado } \\
\text { aos recursos renováveis. Em 2014, inauguramos um } \\
\text { Laboratório de Produtos Químicos Renováveis, voltado a } \\
\text { projetos relacionados à biotecnologia e processos quími- } \\
\text { cos a partir de matéria-prima renovável." }\end{array}$ \\
\hline & $\begin{array}{l}\text { Parcerias para o } \\
\text { desenvolvimen- } \\
\text { to de sistemas } \\
\text { renováveis }\end{array}$ & $\begin{array}{l}\text { “Em 2014, firmamos acordo de cooperação tecnológica } \\
\text { com empresas dos EUA e França, para desenvolver tec- } \\
\text { nologia voltada à produção do isopreno de fonte renová- } \\
\text { vel. Em parcerias com os clientes, o portfólio do plástico } \\
\text { verde cresceu, com o lançamento do polietileno de baixa } \\
\text { densidade para fortalecer as aplicações do produto." }\end{array}$ \\
\hline Gama & $\begin{array}{l}\text { Soluções com } \\
\text { recursos reno- } \\
\text { váveis }\end{array}$ & $\begin{array}{l}\text { "Desenvolvemos e fabricamos produtos que utilizam } \\
\text { alimentação por energia solar. Buscamos também utilizar } \\
\text { matérias-primas como madeira OSB, que são madeiras } \\
\text { reflorestadas e aprovadas no mundo inteiro, sustentavel- } \\
\text { mente ao invés de madeiras comuns." }\end{array}$ \\
\hline Delta & $\begin{array}{l}\text { Soluções com } \\
\text { recursos reno- } \\
\text { váveis }\end{array}$ & $\begin{array}{l}\text { "Temos outro olhar em relação a materiais, substituição } \\
\text { de materiais não renováveis por renováveis, reuso de } \\
\text { materiais, destinação ambientalmente correta de tudo, } \\
\text { sempre procurando a logística reversa, no sentindo de } \\
\text { dar um novo uso para um material após o uso." }\end{array}$ \\
\hline
\end{tabular}

A empresa Alfa incentiva a utilização de combustíveis em seus veículos e busca soluções para a introdução de insumos renováveis em seus produtos. A empresa Beta tem ampliado a sua linha de produtos verdes e investido em parcerias para o desenvolvimento de sistemas renováveis a fim de atingir o seu objetivo de ser reconhecida como líder na fabricação de produtos químicos e resinas termoplásticas a partir de matérias-primas renováveis e permanecer como o maior produtor do mundo de resinas termoplásticas de fonte renovável. As empresas Gama e Delta possuem ações pontuais que visam à inserção de matéria-prima de fonte renovável em seus produtos. 
Ainda não possui grande representatividade a busca por soluções que priorizem a utilização de recursos renováveis. Bocken et al. (2014) destacam a necessidade de redução dos impactos ambientais e aumento da resistência do negócio identificando as limitações de recursos associadas aos recursos não renováveis e sistemas de produção atuais.

O Quadro 9 resume as principais evidências no que se refere à entrega de funcionalidade ao invés de propriedade.

\section{Quadro 9 - Entrega de funcionalidade ao invés de propriedade}

\begin{tabular}{|c|c|c|}
\hline \multicolumn{3}{|c|}{ Entrega de funcionalidade ao invés de propriedade } \\
\hline Empresa & Variáveis & Evidências \\
\hline Alfa & $\begin{array}{l}\text { Plataforma de } \\
\text { serviços }\end{array}$ & $\begin{array}{l}\text { "Criamos uma unidade de negócios, porque tivemos } \\
\text { boas experiências no passado com a oferta de serviços, a } \\
\text { ponto de conseguirmos formatar uma nova unidade que } \\
\text { vai oferecer serviços canalizando várias soluções. Temos } \\
\text { formatado um modelo de troca de comunicação gráfica de } \\
\text { clientes." }\end{array}$ \\
\hline Beta & $\begin{array}{l}\text { Posição na ca- } \\
\text { deia dificulta } \\
\text { a operacio- } \\
\text { nalização do } \\
\text { conceito PSS }\end{array}$ & $\begin{array}{l}\text { "Na venda acho que muito pouco ou nada, porque nós } \\
\text { vendemos resinas termoplásticas que vão ser utilizadas } \\
\text { para produção de outras coisas, está muito longe do con- } \\
\text { sumidor final." }\end{array}$ \\
\hline Gama & $\begin{array}{l}\text { Serviço } \\
\text { agregado ao } \\
\text { produto }\end{array}$ & $\begin{array}{l}\text { "Todos os produtos acompanham softwares, que podem } \\
\text { ser personalizados conforme a necessidade do cliente. } \\
\text { Oferecemos serviço de assessoria para operação, possuí- } \\
\text { mos equipes que trabalham continuamente desenvolven- } \\
\text { do soluções projetadas para as operações e necessidades } \\
\text { únicas de cada cliente." }\end{array}$ \\
\hline Delta & $\begin{array}{l}\text { Serviço } \\
\text { agregado ao } \\
\text { produto }\end{array}$ & $\begin{array}{l}\text { "Nós discutimos várias vezes de que forma a empresa } \\
\text { pode ter serviços também, porque somos especificamente } \\
\text { uma empresa de produtos. O que pode acontecer muitas } \\
\text { vezes, é agregar um serviço ao produto. Não sei como vai } \\
\text { ser no futuro a médio e longo prazo, mas é possível que } \\
\text { possamos ter alguns serviços também, só que muda um } \\
\text { pouco a característica da empresa." }\end{array}$ \\
\hline
\end{tabular}

Em relação à categoria entrega de funcionalidade ao invés de propriedade, apenas a empresa Alfa tem uma unidade de negócios formatada para oferecer serviços aos clientes, e as demais orga- 
nizações possuem serviços agregados aos produtos oferecidos. O entrevistado da empresa Delta coloca que, no futuro, é possível que a empresa venha a oferecer serviços também.

A partir dos resultados, foi possível constatar que o conceito de sistema de produto-serviço (Product-Service System - PSS) ainda está distante da realidade das empresas analisadas, indo de encontro à concepção de Hansen, Grosse-Dunker e Reichwald (2009), ao defenderem a busca por alternativas para a substituição de produtos por serviços, partindo da ideia de que os consumidores não comprem o produto em si, mas, sim, a utilidade oferecida. Tal fato pode ser explicado pela dificuldade de operacionalização do conceito em empresas industriais, que fornecem produtos a intermediários ou ao consumidor final.

O Quadro 10 resume as principais evidências no que tange à adoção do papel de liderança.

\section{Quadro 10 - Adoção de papel de liderança}

\begin{tabular}{|c|c|c|}
\hline \multicolumn{3}{|c|}{ Adoção de papel de liderança } \\
\hline Empresa & Variáveis & Evidências \\
\hline \multirow[b]{2}{*}{ Alfa } & $\begin{array}{l}\text { Bem-estar } \\
\text { dos colabo- } \\
\text { radores }\end{array}$ & $\begin{array}{l}\text { "Oferece políticas e práticas que focam o desenvolvimen- } \\
\text { to, oportunidades de carreira, benefícios e reconhecimen- } \\
\text { to, além de termos vários canais de comunicação." }\end{array}$ \\
\hline & $\begin{array}{l}\text { Seleção de } \\
\text { fornecedo- } \\
\text { res }\end{array}$ & $\begin{array}{l}\text { "Damos preferência à contratação fornecedores brasileiros, } \\
\text { que suprem } 87 \% \text { das necessidades de compras de merca- } \\
\text { dorias e suprimentos. A contratação de fornecedores de } \\
\text { insumos é feita mediante o atendimento de uma série de } \\
\text { exigências relacionadas à gestão de saúde, segurança e } \\
\text { meio ambiente, e da qualidade do produto, custo, prazo } \\
\text { de entrega, e uma atuação em respeito aos princípios } \\
\text { éticos da empresa." }\end{array}$ \\
\hline \multirow[t]{2}{*}{ Beta } & $\begin{array}{l}\text { Seleção de } \\
\text { fornecedo- } \\
\text { res }\end{array}$ & $\begin{array}{l}\text { "Os fornecedores devem seguir os compromissos de } \\
\text { comportamento e ética profissionais expressos no nosso } \\
\text { Código de Conduta. Em decorrência da estrutura descen- } \\
\text { tralizada, cada área é responsável pela gestão dos seus } \\
\text { fornecedores. A empresa ainda propôs um Código de } \\
\text { conduta fornecedores de etanol, quando não existia ainda } \\
\text { uma certificação internacional." }\end{array}$ \\
\hline & $\begin{array}{l}\text { Bem-estar } \\
\text { dos colabo- } \\
\text { radores }\end{array}$ & $\begin{array}{l}\text { "O relacionamento com os integrantes tem como base a } \\
\text { confiança e a valorização do ser humano e seu desejo de } \\
\text { crescer com os desafios profissionais e alcançar novos } \\
\text { horizontes na vida e na carreira." }\end{array}$ \\
\hline
\end{tabular}




\begin{tabular}{|l|l|l|}
\hline \multicolumn{2}{|l|}{ Adoção de papel de liderança } \\
\hline Empresa & Variáveis & Evidências \\
\hline \multirow{5}{*}{ Gama } & $\begin{array}{l}\text { Seleção de } \\
\text { fornecedo- } \\
\text { res }\end{array}$ & $\begin{array}{l}\text { "Temos algumas práticas como fornecedores com certifi- } \\
\text { cações ISO 14001 e OSHAS 18001; Norma Diretiva RoHS, } \\
\text { que restringe uso de diversas substâncias (fornecedor de } \\
\text { LEDS)." }\end{array}$ \\
\cline { 2 - 4 } & $\begin{array}{l}\text { Bem-estar } \\
\text { dos colabo- } \\
\text { radores }\end{array}$ & $\begin{array}{l}\text { "Temos um espaço de lazer e prática de esportes para os } \\
\text { funcionários, estamos construindo campos de futebol e de } \\
\text { vôlei para estimular a prática de esportes, temos convênios } \\
\text { com academias que fornecem desconto para os colabo- } \\
\text { radores e um atendimento nutricional gratuito, ações de } \\
\text { comunicações, com dicas sobre nutrição, qualidade de } \\
\text { vida, prevenção de doenças." }\end{array}$ \\
\hline \multirow{1}{*}{ Delta } & $\begin{array}{l}\text { Bem-estar } \\
\text { dos colabo- } \\
\text { radores }\end{array}$ & $\begin{array}{l}\text { "A empresa reduziu a carga horária de trabalho de 44h se- } \\
\text { manais para 40h, preocupada com o bem-estar. Buscamos } \\
\text { diminuir a 'diferença entre o maior e o menor salário', } \\
\text { toda vez que tem um dissídio coletivo da categoria, as } \\
\text { pessoas com um salário inferior ganham um aumento } \\
\text { maior. As pessoas podem opinar e participar das decisões } \\
\text { da empresa, isso é um ponto muito forte desse modelo } \\
\text { novo, de fazer com as pessoas e não para elas." }\end{array}$ \\
\cline { 2 - 3 } & $\begin{array}{l}\text { Seleção de } \\
\text { fornecedo- } \\
\text { res }\end{array}$ & $\begin{array}{l}\text { "Na empresa temos a ISO 9001, um sistema de gestão inte- } \\
\text { grado da qualidade e nele integramos todas as operações. } \\
\text { Temos um procedimento bem estruturado de seleção e } \\
\text { avaliação de fornecedores, com vários critérios e amplia- } \\
\text { mos, incluindo aspectos de sustentabilidade, então quando } \\
\text { fazemos a seleção." }\end{array}$ \\
\hline
\end{tabular}

A empresa Alfa possui ações a fim de atrair, desenvolver e engajar os seus funcionários visando garantir o seu bem-estar. Além de priorizar a contratação de fornecedores brasileiros, a empresa possui uma série de exigências para a seleção dos fornecedores relacionadas à gestão de saúde, segurança, meio ambiente, qualidade do produto, custo, prazo de entrega, atendimento de princípios éticos e legais e à análise da saúde financeira.

A empresa Beta possui uma política de seleção de fornecedores ancorada no seu código de conduta. Destaca-se que a Beta propôs um código de conduta para fornecedores de etanol, quando não existia ainda uma certificação internacional específica, como forma de reiterar o seu compromisso com os princípios de desenvolvimento sustentável e gerenciar a sua relação com a cadeia do etanol. De acordo com o site da empresa, o documento visa à melhoria contí- 
nua das práticas na produção de etanol e, sobretudo, o respeito às leis brasileiras, seguindo como modelo as boas práticas descritas no Protocolo Agroambiental do Estado de São Paulo, no Pacto Global da ONU, no Zoneamento Agroecológico da Cana-de-Açúcar no Brasil, e no Compromisso Nacional para Aperfeiçoar as Condições de Trabalho na Cana-de-Açúcar. A empresa realiza auditorias nas usinas fornecedoras para assegurar o cumprimento das práticas descritas do Código de Conduta. A organização tem ainda um relacionamento com os seus colaboradores centrado na educação e no desenvolvimento, no fortalecimento da cultura organizacional e na valorização das equipes.

A empresa Gama possui algumas exigências quanto à certificações e normas junto aos fornecedores e promove algumas ações em prol do bem-estar dos funcionários.

A empresa Delta tem o bem-estar como um dos direcionadores do seu posicionamento estratégico, contando com várias práticas direcionadas aos funcionários, como a redução da carga horária de trabalho semanal, políticas para a redução da diferença entre o maior e o menor salário, ferramentas que promovem o diálogo e a discussão, como a Roda Viva, que consiste em uma roda de conversa sobre diversos assuntos. A organização ainda tem uma política rigorosa para a seleção de fornecedores que incluem aspectos socioambientais.

Em geral, é possível perceber que as empresas analisadas adotam práticas que visam ao bem-estar dos seus colaboradores e critérios para a seleção de fornecedores considerando questões legais, éticas e socioambientais. Tal resultado corrobora a visão de Bocken et al. (2014) ao destacarem que a adoção de um papel de liderança para a inovação sustentável requer o envolvimento proativo das partes interessadas para garantir a saúde a longo prazo e o bem-estar.

A seguir, são apresentadas as evidências relacionadas ao modelo de negócios das empresas entrevistadas.

\subsection{Modelo de negócios}

O modelo de negócios das empresas estudadas foi analisado por meio das dimensões proposição de valor da empresa, grau de inovação do modelo de negócios, estrutura da cadeia de suprimentos, 
relacionamento com os clientes e composição do modelo financeiro. O Quadro 11 resume as principais evidências encontradas no que se refere à proposição de valor das organizações.

\author{
Quadro 11- Proposição de valor
}

\begin{tabular}{|c|c|c|}
\hline \multicolumn{3}{|c|}{ Proposição de valor } \\
\hline Empresa & Variáveis & Evidências \\
\hline \multirow[t]{2}{*}{ Alfa } & $\begin{array}{l}\text { Definição } \\
\text { do modelo } \\
\text { de negó- } \\
\text { cios }\end{array}$ & $\begin{array}{l}\text { "Buscamos criar novos negócios, (...) é parte da nossa cultura e por isso } \\
\text { temos um reconhecimento muito 'joia' em inovação, tem um motorzi- } \\
\text { nho funcionando o tempo inteiro, estamos lançando coisas novas, elas } \\
\text { têm o seu ciclo e depois tiramos de linha. Nosso grande modelo de } \\
\text { negócios é o crescimento através da introdução de novos produtos." }\end{array}$ \\
\hline & $\begin{array}{l}\text { Proposição } \\
\text { de valor }\end{array}$ & $\begin{array}{l}\text { "Trazemos a sustentabilidade como valor empresarial, com ações } \\
\text { concretas que temos história para contar, pelo } 3 \mathrm{P} \text {, pela adoção de uma } \\
\text { política que às vezes é até mais rigorosa do que a do país." }\end{array}$ \\
\hline \multirow[b]{2}{*}{ Beta } & $\begin{array}{l}\text { Definição } \\
\text { do modelo } \\
\text { de negó- } \\
\text { cios }\end{array}$ & $\begin{array}{l}\text { "Utilizamos a tecnologia e a inovação para alcançar o desenvolvi- } \\
\text { mento sustentável. O nosso propósito é melhorar a vida das pessoas } \\
\text { criando as soluções sustentáveis da química e do plástico e a nossa } \\
\text { visão estratégica é ser a líder mundial da química sustentável." }\end{array}$ \\
\hline & $\begin{array}{l}\text { Proposição } \\
\text { de valor }\end{array}$ & $\begin{array}{l}\text { "Os macro-objetivos estratégicos refletem a preocupação da empre- } \\
\text { sa com os três pilares da sustentabilidade, que estão relacionados a } \\
\text { metas e indicadores. O nosso propósito foi definido recentemente e } \\
\text { está muito atrelado à sustentabilidade, é melhorar a vida das pessoas, } \\
\text { criando (aí vem a inovação) soluções sustentáveis a partir da química } \\
\text { do plástico". }\end{array}$ \\
\hline \multirow[b]{2}{*}{ Gama } & $\begin{array}{l}\text { Definição } \\
\text { do modelo } \\
\text { de negó- } \\
\text { cios }\end{array}$ & $\begin{array}{l}\text { "A visão, missão, valores e princípios que norteiam as estratégias de } \\
\text { posicionamento de mercado são focados na inovação. Desde a funda- } \\
\text { ção, temos como meta estratégica produzir e comercializar produtos e } \\
\text { serviços inovadores visando superar as expectativas dos clientes." }\end{array}$ \\
\hline & $\begin{array}{l}\text { Proposição } \\
\text { de valor }\end{array}$ & $\begin{array}{l}\text { "Com a visão de negócio de ser referência em tecnologias para sistemas } \\
\text { de informação e entretenimento por muitas gerações, buscamos desen- } \\
\text { volver soluções para aumentar a lucratividade de nossos clientes, ao } \\
\text { mesmo tempo em que os produtos são desenvolvidos visando proteger } \\
\text { o meio ambiente, e oferecer benefícios sociais aos usuários finais." }\end{array}$ \\
\hline \multirow[b]{2}{*}{ Delta } & $\begin{array}{l}\text { Definição } \\
\text { do modelo } \\
\text { de negó- } \\
\text { cios }\end{array}$ & $\begin{array}{l}\text { "O modelo de negócios é dedicado a produzir coisas que tenham } \\
\text { relevância para as pessoas. Entendendo que a cooperação e a parceria } \\
\text { são essenciais para criação de produtos e serviços relevantes para a } \\
\text { sociedade, assumimos o compromisso institucional de unir pessoas e } \\
\text { organizações para criar soluções sustentáveis." }\end{array}$ \\
\hline & $\begin{array}{l}\text { Proposição } \\
\text { de valor }\end{array}$ & $\begin{array}{l}\text { "O nosso compromisso institucional reflete essa inserção de critérios } \\
\text { econômicos, sociais e ambientais, pois acreditamos muito que, unindo } \\
\text { pessoas e organizações, a partir de complementaridades, podere- } \\
\text { mos construir soluções que possam indicar novos patamares de uso, } \\
\text { criando novas facilidades e ampliando o acesso de mais segmentos da } \\
\text { sociedade a elas." }\end{array}$ \\
\hline
\end{tabular}


A empresa Alfa possui o seu modelo de negócios alicerçado no crescimento, a partir da introdução de novos produtos. O seu crescimento estratégico está atrelado à sustentabilidade como proposta de valor, e a empresa atua de forma harmônica por meio de ações concretas nos pilares econômico, social e ambiental.

A empresa Beta está inserida no setor químico e petroquímico, tendo participação relevante em inúmeras cadeias produtivas, sendo essencial para o desenvolvimento do país. Desse modo, o seu modelo de negócios busca a criação de soluções sustentáveis para a melhoria da vida das pessoas em setores como saúde, moradia, alimentação, mobilidade, entre outros. O propósito empresarial de melhorar a vida das pessoas criando soluções sustentáveis a partir da química do plástico, com os macro-objetivos estratégicos e com a estratégia empresarial, refletem a preocupação com os três pilares da sustentabilidade e a sua proposta de valor.

A empresa Gama possui o seu modelo de negócios focado na inovação, e a sua proposição de valor baseia-se na busca por ser referência em tecnologias para sistemas de informação e entretenimento por muitas gerações. Para isso, desenvolve soluções a fim de aumentar a lucratividade dos clientes, ao mesmo tempo em que os produtos são produzidos visando proteger o meio ambiente e oferecer benefícios sociais aos usuários finais.

A empresa Delta possui um modelo de negócios alicerçado na produção de produtos relevantes para a sociedade e na busca pelo bem-estar das pessoas, tendo como proposta de valor o compromisso institucional de unir pessoas e organizações para criar soluções sustentáveis a partir da inserção de critérios econômicos, sociais e ambientais, visando a um "mundo de um jeito bom para todo o mundo".

De acordo com Teece (2010), a essência de um modelo de negócios está na definição da maneira pela qual a empresa agrega valor aos clientes, atrai clientes para pagar o valor estabelecido e converte os pagamentos em lucro. Partindo desse conceito, a partir dos dados é possível perceber que o modelo de negócios das empresas Alfa e Gama possui um maior foco em inovação, o da empresa Beta está ancorado na busca por soluções sustentáveis por meio da química do plástico e o da empresa Delta visa ao desenvolvimento de pro- 
dutos úteis e à busca pelo bem-estar das pessoas. Ainda foi possível constatar que a proposição de valor de todas as empresas analisadas contempla critérios relacionados à sustentabilidade.

O Quadro 12 resume as principais evidências no que tange ao grau de inovação do modelo de negócios das empresas analisadas em função dos investimentos em sustentabilidade.

\section{Quadro 12 - Grau de inovação do modelo de negócios}

\begin{tabular}{|c|c|c|}
\hline \multicolumn{3}{|c|}{ Grau de inovação do modelo de negócios } \\
\hline Empresa & Variáveis & Evidências \\
\hline Alfa & $\begin{array}{l}\text { Melhorias contínuas } \\
\text { no modelo de negó- } \\
\text { cios em função da } \\
\text { sustentabilidade }\end{array}$ & $\begin{array}{l}\text { "E um processo histórico (...). Estamos em um } \\
\text { nível de maturidade super "joia", temos uma } \\
\text { introdução de novos produtos com critérios extre- } \\
\text { mamente rígidos e fundamentados em parâmetros } \\
\text { de sustentabilidade e está funcionando muito bem. } \\
\text { Tem como melhorar? Tem, muito, mas em oferta } \\
\text { de negócios, de encontrar brechas para alavancar } \\
\text { resultados com a sustentabilidade e nós encontra- } \\
\text { mos algumas restrições de aceitação de mercado } \\
\text { dessas soluções". }\end{array}$ \\
\hline Beta & $\begin{array}{l}\text { Modelo de negócios } \\
\text { adaptado para incluir } \\
\text { a sustentabilidade }\end{array}$ & $\begin{array}{l}\text { “Quando você fala em modelo de negócio, é como } \\
\text { mudar o esqueleto, e não é isso. Usando a mesma } \\
\text { forma de fazer a nossa gestão, ela se adaptou des- } \\
\text { de o início da empresa, então algumas mudanças } \\
\text { aconteceram no período para determinados negó- } \\
\text { cios. Não é que tenhamos mudado completamente } \\
\text { o modelo de negócios, mesma forma, porém com } \\
\text { algumas adaptações que aconteceram." }\end{array}$ \\
\hline Gama & $\begin{array}{l}\text { Modelo de negócios } \\
\text { inovador }\end{array}$ & $\begin{array}{l}\text { "Desde o início, nosso modelo de negócios é } \\
\text { baseado em inovação. Acredito que o modelo de } \\
\text { negócios é algo vivo, que surge em interatividade } \\
\text { direta com as necessidades da sociedade, do mun- } \\
\text { do e do meio ambiente." }\end{array}$ \\
\hline Delta & $\begin{array}{l}\text { Mudança radical no } \\
\text { modelo de negócios } \\
\text { em função da susten- } \\
\text { tabilidade }\end{array}$ & $\begin{array}{l}\text { "A empresa mudou o seu modelo de negócio } \\
\text { em } 2009 \text {, vinha de um modelo tradicional, onde } \\
\text { o lucro era o principal objetivo, de fazer para o } \\
\text { mercado, de não fazer com as pessoas, nem con- } \\
\text { sultá-las, simplesmente desenvolver um produto e } \\
\text { lançar sem saber se efetivamente teria um retorno } \\
\text { ou não, porque não foi conversado antes com } \\
\text { quem vai usar. O modelo passou a ser mais amplo, } \\
\text { no sentido de valorizar muito mais as questões } \\
\text { socioambientais na tomada de decisão, (...) muito } \\
\text { mais calcado em questões de pessoas e meio am- } \\
\text { biente do que antes." }\end{array}$ \\
\hline
\end{tabular}


Em relação ao grau de inovação do modelo de negócios em função dos investimentos em sustentabilidade, foi possível constatar que as empresas Alfa e Beta realizaram melhorias contínuas e adaptações em seus modelos a fim de introduzir a sustentabilidade. A empresa Gama possui um modelo de negócios baseado na inovação desde a sua criação. E a empresa Delta modificou de forma radical o seu modelo de negócios em função de um novo posicionamento estratégico assumido no ano de 2009, que busca o bem-estar e a valorização da vida. Desse modo, a organização possui um modelo de negócios diferenciado, com ênfase em questões éticas, sociais e ambientais, que prioriza o bem-estar das pessoas e do meio ambiente sem a necessidade de explorá-los de forma negativa.

Nesse sentido, os resultados constataram que as empresas Alfa e Beta vêm realizando adaptações ao longo do tempo em seus modelos de negócios a fim de contemplar os critérios da sustentabilidade. $\mathrm{Na}$ empresa Gama, não foi possível identificar modificações no modelo de negócios em decorrência da sustentabilidade. E, na organização Delta, verificou-se uma mudança radical no modelo de negócios em virtude de um novo posicionamento estratégico, no qual o bem-estar das pessoas passa a ser o eixo norteador da empresa.

Os resultados vão ao encontro do estudo de Schaltegger, Lüdeke-Freund e Hansen (2012), ao destacarem que é necessário entender que a orientação dos negócios para a sustentabilidade de forma contínua pode requerer a adaptação ou até mesmo a mudança radical do modelo de negócios da empresa.

O Quadro 13 resume as principais evidências no que se refere à cadeia de suprimentos. 


\section{Quadro 13 - Cadeia de suprimentos}

\begin{tabular}{|c|c|c|}
\hline Empresa & Variáveis & Evidências \\
\hline Alfa & $\begin{array}{l}\text { Sustentabilida- } \\
\text { de na cadeia de } \\
\text { suprimentos }\end{array}$ & $\begin{array}{l}\text { "Temos critérios para a seleção e desenvolvimento de } \\
\text { parceiras com os fornecedores para ações sustentáveis. Em } \\
\text { 2014, iniciamos o processo para ser signatária do Instituto } \\
\text { InPacto, que tem o objetivo de fortalecer, ampliar e dar sus- } \\
\text { tentabilidade às ações do Pacto Nacional pela Erradicação } \\
\text { do Trabalho Escravo, tangibilizando o compromisso com } \\
\text { o desenvolvimento de uma cadeia de suprimentos mais } \\
\text { sustentável." }\end{array}$ \\
\hline Beta & $\begin{array}{l}\text { Sustentabilida- } \\
\text { de na cadeia de } \\
\text { suprimentos }\end{array}$ & $\begin{array}{l}\text { "Temos um Código de Conduta para Fornecedores de } \\
\text { Etanol, elaborado a partir de boas práticas de gerenciamen- } \\
\text { to social e ambiental no segmento. Todo o fornecedor deve } \\
\text { demonstrar comprometimento e capacidade de gestão de } \\
\text { requisitos de Saúde, Segurança e Meio Ambiente (SSMA), } \\
\text { Qualidade e Produtividade, que são acompanhados e ava- } \\
\text { liados por meio de um sistema de análise de desempenho } \\
\text { de fornecedor e pelo Sistema de Avaliação de Segurança, } \\
\text { Saúde, Meio Ambiente e Qualidade da Abiquim." }\end{array}$ \\
\hline Gama & $\begin{array}{l}\text { Práticas de } \\
\text { responsabilida- } \\
\text { de ambiental } \\
\text { e social de } \\
\text { fornecedores }\end{array}$ & $\begin{array}{l}\text { "A empresa possui algumas práticas de responsabilida- } \\
\text { de ambiental e social de alguns fornecedores, como por } \\
\text { exemplo: utilização de embalagens recicladas; reciclagem } \\
\text { eletrônica; exigência da norma Diretiva RoHS, que restrin- } \\
\text { ge uso de diversas substâncias (fornecedor de LEDS) e de } \\
\text { certificações ISO } 14001 \text { e OSHAS 18001." }\end{array}$ \\
\hline Delta & $\begin{array}{l}\text { Sustentabilida- } \\
\text { de na cadeia de } \\
\text { suprimentos }\end{array}$ & $\begin{array}{l}\text { "Somos parte da cadeia, compramos de um fornecedor, } \\
\text { vendemos para o cliente. A cadeia produtiva é muito } \\
\text { extensa e esse é o ponto fundamental da sustentabilidade, } \\
\text { um dia a sustentabilidade vai atingir desde o fornecedor de } \\
\text { uma matéria-prima até o usuário. Esse trabalho na cadeia } \\
\text { de suprimentos é um desafio que temos e que pretendemos } \\
\text { ampliar, melhoramos bastante em vários aspectos com os } \\
\text { nossos clientes, com os nossos fornecedores diretos, mas } \\
\text { ainda é necessário dar o passo a mais, isso é um caminho } \\
\text { sem fim." }\end{array}$ \\
\hline
\end{tabular}

A preocupação com uma cadeia de suprimentos sustentável foi observada nas empresas Alfa, Beta e Delta que, além de possuírem critérios para a seleção de fornecedores incluindo variáveis socioambientais já apresentados, também têm ações que visam ampliar essa questão ao longo de toda a cadeia, ou seja, desde a aquisição da matéria-prima até o descarte do produto final. Na empresa Gama, 
foi possível identificar apenas algumas questões pontuais junto a alguns fornecedores.

Em relação à cadeia de suprimentos das empresas entrevistadas, foi possível confirmar as premissas de Boons e Lüdeke-Freund (2013), uma vez que se constatou o envolvimento dos fornecedores na gestão sustentável da cadeia, tendo em vista que as empresas possuem práticas nesse sentido.

O Quadro 14 resume as principais evidências no que tange ao relacionamento com os clientes.

\section{Quadro 14 - Relacionamento com os clientes}

\begin{tabular}{|c|c|c|}
\hline \multicolumn{3}{|c|}{ Relacionamento com os clientes } \\
\hline Empresa & Variáveis & Evidências \\
\hline Alfa & $\begin{array}{l}\text { Centro técnico } \\
\text { para clientes }\end{array}$ & $\begin{array}{l}\text { "Com o objetivo de aproximar a empresa dos clientes, } \\
\text { temos o Centro Técnico para Clientes que expõe os } \\
\text { produtos inovadores e interage com os consumidores em } \\
\text { prol do desenvolvimento de soluções para suas neces- } \\
\text { sidades em } 24 \text { diferentes laboratórios. É recente a nossa } \\
\text { parceria do grupo de LCM e taxologia para levar aos } \\
\text { clientes a nossa preocupação com a composição química, } \\
\text { com os riscos e tudo mais." }\end{array}$ \\
\hline Beta & $\begin{array}{l}\text { Sustentabilidade } \\
\text { no relacionamento } \\
\text { com clientes }\end{array}$ & $\begin{array}{l}\text { "Temos o Programa de Incentivo à Cadeia do Plástico } \\
\text { (PICPlast), o Programa Visio, lançamos uma plataforma } \\
\text { de comunicação para divulgar as vantagens do uso do } \\
\text { plástico em embalagens aos clientes." }\end{array}$ \\
\hline Gama & $\begin{array}{l}\text { Assessoria no de- } \\
\text { senvolvimento dos } \\
\text { projetos }\end{array}$ & $\begin{array}{l}\text { "O relacionamento com os clientes com base nos desa- } \\
\text { fios da sustentabilidade se dá por meio da assessoria no } \\
\text { desenvolvimento de cada projeto. É essencial a inovação } \\
\text { para se adaptar ao mercado e às necessidades dos clien- } \\
\text { tes individuais. A personalização de produtos e serviços } \\
\text { é muito importante para suprir as necessidades de cada } \\
\text { cliente, então personalizamos os produtos e serviços } \\
\text { e temos vários produtos com o foco de economia de } \\
\text { recursos." }\end{array}$ \\
\hline Delta & $\begin{array}{l}\text { Conversas com } \\
\text { clientes }\end{array}$ & $\begin{array}{l}\text { "Não existe na nossa visão uma forma, um mecanismo } \\
\text { ou uma fórmula melhor do que a conversa, o diálogo, } \\
\text { para que a sustentabilidade aconteça, e então conversa- } \\
\text { mos com clientes, vamos até os clientes." }\end{array}$ \\
\hline
\end{tabular}

A empresa Alfa possui um Centro Técnico para interação com os clientes por meio do qual discute questões relacionadas à sustentabilidade. 
A empresa Beta tem ações a fim de apoiar os clientes no desenvolvimento de soluções socioambientais e fomentar a percepção do plástico como solução para o desenvolvimento sustentável em decorrência da sua contribuição para melhorar a vida das pessoas. Desse modo, além de possuir alguns programas que tratam do assunto, a empresa lançou recentemente uma plataforma de comunicação para divulgar aos clientes as vantagens do uso do plástico em embalagens e outra que busca fomentar negócios e soluções que envolvam a reciclagem do plástico por meio de parcerias com organizações.

Na empresa Gama, o relacionamento com os clientes com base nos desafios da sustentabilidade ocorre por meio da assessoria no desenvolvimento de cada projeto. Na empresa Delta, a relação é baseada na conversa e no contato direto visando difundir a cultura da sustentabilidade.

Assim, foi verificado que as empresas entrevistadas se relacionam com os seus clientes com base nos desafios da sustentabilidade, indo ao encontro da visão de Boons e Lüdeke-Freund (2013), ao ressaltarem a necessidade de motivar os clientes a assumir a sua responsabilidade pelo consumo e se envolverem com os desafios da sustentabilidade.

O Quadro 15 resume as principais evidências relacionadas ao modelo financeiro das empresas entrevistadas.

\section{Quadro 15 - Modelo financeiro}

\begin{tabular}{|c|c|c|}
\hline \multicolumn{3}{|c|}{ Modelo financeiro } \\
\hline Empresa & Variáveis & Evidências \\
\hline \multirow[t]{2}{*}{ Alfa } & $\begin{array}{l}\text { O modelo } \\
\text { financeiro } \\
\text { contem- } \\
\text { pla a } \\
\text { sustenta- } \\
\text { bilidade }\end{array}$ & $\begin{array}{l}\text { "Se desmembrarmos a sustentabilidade nos seus três pilares } \\
\text { principais, o econômico é o que todo mundo mais conhe- } \\
\text { ce, a empresa tem que ter fôlego, músculo econômico. O } \\
\text { ambiental tem um suporte muito grande dos valores da } \\
\text { empresa, tem história, está acontecendo há bastante tempo. } \\
\text { O social tem o impacto da atividade do Instituto. Agora, } \\
\text { o bonito mesmo é conseguir empacotar tudo isso em um } \\
\text { projeto e vender como oferta de valor, esse é o melhor dos } \\
\text { mundos." }\end{array}$ \\
\hline & $\begin{array}{l}\text { Remu- } \\
\text { neração } \\
\text { variável }\end{array}$ & $\begin{array}{l}\text { "A remuneração variável tem impacto de uma seleção de } \\
\text { indicadores que vai no scorecard particular. Temos um crité- } \\
\text { rio global que são os atributos de sustentabilidade e dessa } \\
\text { forma enxergamos o desdobramento do esforço de sustenta- } \\
\text { bilidade na remuneração." }\end{array}$ \\
\hline
\end{tabular}




\begin{tabular}{|c|c|c|}
\hline \multirow[t]{2}{*}{ Beta } & $\begin{array}{l}\text { O modelo } \\
\text { financeiro } \\
\text { contem- } \\
\text { pla a } \\
\text { sustenta- } \\
\text { bilidade }\end{array}$ & $\begin{array}{l}\text { "Queremos continuar crescendo, ser uma das três maiores } \\
\text { do mundo, mas de uma forma sustentável do ponto de } \\
\text { vista financeiro, por isso a manutenção no investment grade, } \\
\text { entendemos que uma empresa tem que ter lucro, não tem } \\
\text { como existir sem lucro, contudo o lucro tem que ser susten- } \\
\text { tável, por isso que esse conjunto de dez macro-objetivos que } \\
\text { se complementam é que define nossa estratégia." }\end{array}$ \\
\hline & $\begin{array}{l}\text { Remu- } \\
\text { neração } \\
\text { variável }\end{array}$ & $\begin{array}{l}\text { "Todos os integrantes têm um plano de ação individual, } \\
\text { requisito para receberem sua remuneração variável, que é } \\
\text { atrelada ao nível de cumprimento das metas e ao alinha- } \\
\text { mento aos valores da empresa." }\end{array}$ \\
\hline Gama & $\begin{array}{l}\text { Participa- } \\
\text { ção nos } \\
\text { resultados }\end{array}$ & $\begin{array}{l}\text { "Um mecanismo de incentivo é o programa de participação } \\
\text { nos resultados para os colaboradores." }\end{array}$ \\
\hline \multirow[t]{2}{*}{ Delta } & $\begin{array}{l}\text { Redu- } \\
\text { ção da } \\
\text { diferença } \\
\text { entre o } \\
\text { maior e } \\
\text { o menor } \\
\text { salário }\end{array}$ & $\begin{array}{l}\text { "Temos um indicador que visa reduzir a diferença entre o } \\
\text { menor e o maior salário, que evolui na medida em que va- } \\
\text { mos construindo um novo modelo de negócio que permita } \\
\text { uma remuneração coerente ao propósito da empresa." }\end{array}$ \\
\hline & $\begin{array}{l}\text { O modelo } \\
\text { financeiro } \\
\text { contem- } \\
\text { pla a } \\
\text { sustenta- } \\
\text { bilidade }\end{array}$ & $\begin{array}{l}\text { "Não posso simplesmente lançar um produto só pensando } \\
\text { no lucro, preciso antes saber quais suas matérias-primas, se } \\
\text { essas matérias-primas são renováveis ou não, de onde elas } \\
\text { vão vir, se o fornecedor está de acordo com as legislações } \\
\text { necessárias." }\end{array}$ \\
\hline
\end{tabular}

A empresa Alfa busca um crescimento financeiro atuando nos três pilares da sustentabilidade e oferece uma remuneração justa e equiparada à praticada no mercado, possui uma política de remuneração variável com base em indicadores definidos para cada funcionário e adota um critério global por meio de atributos de sustentabilidade a fim de visualizar o desdobramento desses esforços na remuneração.

A empresa Beta busca um crescimento financeiro sustentável expresso nos dez macro- objetivos que definem a sua estratégia e ainda conta com uma política de remuneração variável baseada em indicadores.

A empresa Gama também apresenta uma política de remuneração variável baseada em uma autoavaliação e em uma avaliação pelo supervisor direto de cada colaborador. A empresa Delta possui 
políticas a fim de reduzir a diferença entre o menor e o maior salário, bem como, um modelo financeiro que reflete a sua preocupação com a sustentabilidade, de modo que, na visão do entrevistado, a empresa não pode simplesmente lançar um produto pensando no lucro, mas se faz necessário avaliar o contexto socioambiental desde as matérias-primas a serem utilizadas até a utilidade desse produto para o cliente final.

Boons e Lüdeke-Freund (2013) sugerem que o modelo financeiro deve refletir uma distribuição adequada de custos e benefícios econômicos entre os atores envolvidos no modelo de negócios, o que pode ser observado nas quatro empresas analisadas. Contudo, o alinhamento das dimensões da sustentabilidade com o modelo financeiro das empresas ficou mais evidente nas empresas Alfa, Beta e Delta.

A seguir, são apresentadas as evidências relacionadas ao desempenho empresarial.

\subsection{Desempenho empresarial}

No que tange ao desempenho empresarial, buscou-se analisar a sua forma de mensuração pelas empresas analisadas. E ainda se procurou identificar se havia relação entre os investimentos em sustentabilidade com o desempenho empresarial. O Quadro 16 resume as principais evidências encontradas sobre esta categoria de análise.

\section{Quadro 16 - Desempenho empresarial}

\begin{tabular}{|c|c|c|}
\hline \multicolumn{3}{|r|}{ Desempenho empresarial } \\
\hline Empresa & Variáveis & Evidências \\
\hline & $\begin{array}{l}\text { Sistema de indi- } \\
\text { cadores }\end{array}$ & $\begin{array}{l}\text { "Temos um controle de indicadores puxado pelos objetivos, } \\
\text { uma série de indicadores estabelecidos e monitorados." }\end{array}$ \\
\hline Alfa & $\begin{array}{l}\text { Relação da ino- } \\
\text { vação sustentável } \\
\text { com o desempe- } \\
\text { nho }\end{array}$ & $\begin{array}{l}\text { "Ao longo dos anos todo o investimento em inovação susten- } \\
\text { tável teve um impacto positivo no desempenho. Esse diálogo } \\
\text { para desenvolver soluções para as necessidades dos clientes } \\
\text { teve uma evolução muito boa, o que tem que acontecer em } \\
\text { maior escala é a taxa de sucesso, porque temos ainda várias } \\
\text { coisas aquardando a hora certa de entrar no mercado." }\end{array}$ \\
\hline
\end{tabular}




\begin{tabular}{|l|l|l|}
\hline \multirow{1}{*}{ Beta } & $\begin{array}{l}\text { Sistema de indi- } \\
\text { cadores }\end{array}$ & $\begin{array}{l}\text { "A empresa possui uma série de indicadores que são con- } \\
\text { trolados e monitorados. Nossa gestão é com base em uma } \\
\text { tecnologia empresarial que tem orientação do acionista, a } \\
\text { necessidade dos clientes e das partes interessadas." }\end{array}$ \\
\cline { 2 - 3 } & $\begin{array}{l}\text { Relação da ino- } \\
\text { vação sustentável } \\
\text { com o desempe- } \\
\text { nho }\end{array}$ & $\begin{array}{l}\text { "O impacto positivo depende do tipo de investimento, por } \\
\text { exemplo, investimentos que reduzem o consumo energéti- } \\
\text { co... Há sim projeto que a sustentabilidade está contribuindo } \\
\text { economicamente, há projetos que nem tanto, e ficamos aguar- } \\
\text { dando o melhor momento para fazer o investimento, mas a } \\
\text { busca é para que todo projeto, só aconteça se gerar benefícios } \\
\text { econômicos, sociais e ambientais ao mesmo tempo." }\end{array}$ \\
\hline Gama & $\begin{array}{l}\text { Sistema de indi- } \\
\text { cadores }\end{array}$ & $\begin{array}{l}\text { "Temos uma série de indicadores de desempenho. Na fábri- } \\
\text { ca, em todos os setores, temos murais com os indicadores e } \\
\text { eles são enviados por e-mail, monitorados mensalmente por } \\
\text { um grupo multidisciplinar de vários setores. E realizamos } \\
\text { reuniões para fazer brainstorming e trocar ideias sobre cada } \\
\text { um dos indicadores. Todo o investimento em inovação tem } \\
\text { trazido ótimos resultados e grande crescimento da empresa } \\
\text { durante seus 12 anos de existência." }\end{array}$ \\
\hline Delta & $\begin{array}{l}\text { "Temos uma série de indicadores de desempenho que con- } \\
\text { trolamos mensalmente. Essa mudança no modelo de negócio } \\
\text { lação da inovação } \\
\text { sustentável com o } \\
\text { desempenho } \\
\text { trouxe questionamentos, pessoas que achavam que a empresa } \\
\text { iria quebrar, por tirar um pouco o foco e o pé do acelera- } \\
\text { dor nas vendas. E quem pensou isso quebrou a cara porque } \\
\text { estamos melhor financeiramente do que antes, melhorando a } \\
\text { cada ano, inclusive nesse cenário de possível crise." }\end{array}$ \\
\hline
\end{tabular}

No que se refere ao desempenho empresarial, a empresa Alfa possui um sistema de indicadores direcionados pelos seus objetivos estratégicos que são monitorados constantemente. Na concepção do entrevistado, ao longo dos anos, todo o investimento em inovação e sustentabilidade teve um impacto positivo no desempenho empresarial, de modo que o diálogo com o consumidor para o desenvolvimento de soluções sustentáveis evoluiu bastante nos últimos anos, porém ainda se faz necessária uma maior aceitação de produtos sustentáveis pela cadeia como um todo.

A empresa Beta possui uma série de indicadores que são controlados, monitorados e estão ligados ao programa de ação de cada indivíduo, que, por sua vez, está atrelado à política de remuneração variável da empresa. Na visão do entrevistado, o impacto positivo da sustentabilidade no desempenho depende do tipo de investimento, e algumas ações acarretam diretamente redução de custo e benefício econômico, por exemplo, investimentos para a redução do consu- 
mo energético. Contudo, os impactos decorrentes de investimentos em novos produtos sustentáveis dependem da reação do mercado. De modo geral, os produtos lançados pela companhia têm obtido uma resposta positiva do mercado, porém alguns produtos estão aguardando o melhor momento para o lançamento, uma vez que a empresa busca que todo projeto gere benefícios econômicos, sociais e ambientais ao mesmo tempo.

A empresa Gama possui uma série de indicadores para mensuração do desempenho, que são monitorados mensalmente por um grupo multidisciplinar, expostos nos murais de todos os setores e enviados por e-mail. Todo o investimento da empresa em inovação tem trazido excelentes resultados e crescimento, de modo que, em 2012, a empresa duplicou o seu faturamento em relação ao ano anterior.

A empresa Delta possui uma série de indicadores de desempenho que controla mensalmente e considera que a mudança no seu modelo de negócio trouxe impactos positivos, tendo em vista que a organização vem apresentando melhores resultados financeiros do que antes da mudança, em virtude de que as decisões estratégicas vêm sendo pautadas na ética e na sustentabilidade.

A partir do exposto, pode-se perceber que todas as empresas analisadas possuem sistemas de indicadores para fins de mensuração de desempenho. Tais indicadores são monitorados e servem de parâmetros para as decisões das organizações, consistindo em instrumentos que auxiliam na mensuração do desempenho empresarial e são constituídos por uma ou mais variáveis que, associadas, revelam significados mais amplos sobre os fenômenos a que se referem, permitindo o acompanhamento dos interesses da empresa e possibilitando o planejamento de ações visando a melhorias de desempenho (VILLAS BÔAS, 2011; CALLADO, 2010).

Sobre a relação da inovação sustentável com o desempenho empresarial, foi possível evidenciá-la de forma direta nas empresas Alfa, Beta e Delta. Na empresa Gama, há uma preocupação com a sustentabilidade e práticas socioambientais, contudo o desempenho positivo é decorrente principalmente da postura inovadora, de acordo com a entrevistada. 
De forma geral, os achados do estudo confirmam a visão de Aguilera-Caracuel e Ortiz de-Mandojana (2013), ao ressaltarem que a inovação sustentável incorpora melhorias tecnológicas que podem propiciar a economia de energia, a minimização da poluição, a reciclagem de resíduos, o desenvolvimento de produtos verdes e a gestão ambiental corporativa. Esse tipo de inovação também contribui para a sustentabilidade do negócio, uma vez que, potencialmente, possui um efeito positivo nos resultados financeiros, sociais e ambientais de uma empresa.

\section{CONSIDERAÇõeS FINAIS}

Ao analisar as práticas de empresas do Brasil, percebe-se que a postura estratégica para a inovação sustentável é proativa em produto e processo nas empresas brasileiras. De acordo com as proposições de Schaltegger, Lüdeke-Freund e Hansen (2012), as empresas que operam priorizando essas estratégias integram a sustentabilidade à lógica de geração de receita e ao negócio principal da empresa e buscam a liderança por meio do seu desempenho sustentável, que está diretamente relacionado com as suas ações inovadoras.

Desse modo, foi possível constatar que, nas empresas brasileiras analisadas, a sustentabilidade está presente na concepção da estratégia e os esforços de inovação, tanto em produto como em processo, estão alinhados aos objetivos do desenvolvimento sustentável.

As empresas possuem práticas direcionadas à integração das comunidades locais e interação com os stakeholders, o que representa um envolvimento com as partes interessadas. Também no que tange ao desenvolvimento em soluções sustentáveis, nas empresas brasileiras, foram encontradas práticas direcionadas a produtos e processos.

Todas as empresas brasileiras possuem ações para a maximização da eficiência energética, hídrica e redução das emissões. No que se refere à criação de valor a partir do desperdício, identificou-se que as empresas possuem práticas de gerenciamento de resíduos visando à sua destinação correta e reciclagem sempre que possível.

A respeito da substituição por processos renováveis e naturais, verificou-se que duas empresas brasileiras possuem políticas empresariais prioritariamente voltadas para a utilização de recursos 
renováveis, enquanto as outras duas têm algumas ações pontuais nesse sentido.

Alternativas para a substituição de produtos por serviços - sistema de produto-serviço (Product-Service System - PSS) não foram encontradas nas empresas analisadas, evidenciando que esse conceito é pouco aplicável a empresas industriais.

Ainda, as empresas possuem práticas para o bem-estar dos colaboradores e políticas para a seleção de seus fornecedores.

Constatou-se que as empresas possuem uma adoção de práticas de inovação sustentável, tendo como base as ideias de Hall e Vredenburg (2003) e de Charter e Clark (2007), ao defenderem que a inovação direcionada para o desenvolvimento sustentável contrasta com a forma convencional orientada para o mercado e requer tanto a incorporação das restrições oriundas das pressões sociais e ambientais como a inclusão de uma visão que considere também as futuras gerações, devendo ser integrada aos sistemas de geração de ideias da empresa a partir de pesquisa e desenvolvimento (P\&D) e comercialização.

Em relação à proposição de valor relacionada a critérios econômicos, sociais e ambientais, nas empresas brasileiras foi possível evidenciar essa relação em pelo menos três das quatro empresas entrevistadas.

Nas empresas brasileiras, foi possível identificar modificações do modelo de negócios a partir das atividades e decisões de sustentabilidade, envolvimento dos fornecedores na gestão sustentável da cadeia de suprimentos e relacionamento com o cliente considerando os desafios da sustentabilidade.

Observou-se que o modelo financeiro reflete uma distribuição adequada de custos e benefícios econômicos entre os stakeholders, de modo que há inserção dos critérios da sustentabilidade no modelo de negócios nas empresas analisadas.

As empresas possuem indicadores a fim de mensurar e monitorar o desempenho empresarial, podendo ser observada uma relação do desempenho com os investimentos em sustentabilidade.

A partir das evidências, é possível perceber que as empresas vislumbram a inovação sustentável como questão estratégica, constatando-se uma relação com o modelo de negócios e o desempenho empresarial. 


\section{REFERÊNCIAS}

AGUILERA-CARACUEL, J.; ORTIZ-DE-MANDOJANA, N. Green Innovation and Financial Performance: An Institutional Approach. Organization \& Environment, v. 26, n. 4, p. 365385, 2013.

AMIT, R.; ZOTT, C. Value creation in E-business. Strategic Management Journal, v. 22, n. 6-7, p. 493-520, 2001.

ARAGÓN-CORREA, J. A.; HURTADO-TORRES, N.; SHARMA, S.; GARCÍA-MORALES, V. J. Environmental strategy and performance in small firms: A resource-based perspective. Journal of Environmental Management, v. 86, n. 1, p. 88-103, 2008.

AYUSO, S.; RODRÍGUEZ, M. Á.; GARCÍA-CASTRO, R.; ARIÑO, M. A. Does stakeholder engagement promote sustainable innovation orientation? Industrial Management \& Data Systems, Wembley, v. 111, n. 9, p. 1399-1417, 2011.

BARDIN, L. Análise de conteúdo. Trad. Luís Antero Reto, Augusto Pinheiro. São Paulo: Edições 70, 2011.

Beltramello, A.; HAiE-FAYle, L.; PILAT, D. Why New Business Models Matter for Green Growth. OECD Green Growth Papers. OECD Publishing, Paris, 2013.

BOCKEN, N. M. P.; SHORT, S.W.; RANA, P.; EVANS, S.. A literature and practice review to develop sustainable business model archetypes. Journal of Cleaner Production, v. 65, p. 42-56, 2014.

BOONS, F. A. A. Creating Ecological Value. An Evolutionary Approach to Business Strategies and the Natural Environment. Elgar, Cheltenham, 2009.

BOONS, F.; LÜDEKE-FREUND, F. Business models for sustainable innovation: state-of-the-art and steps towards a research agenda. Journal of Cleaner Production, v. 45, p. 9-19, 2013.

BROWN, H. S.; DE JONG, M.; LEVY, D. L. Building institutions based on information disclosure: lessons from GRI's sustainability reporting. Journal of Cleaner Production, v. 17, n. 6, p. 571-580, 2009.

CALLADO, A. L. C. Modelo de mensuração de sustentabilidade empresarial: uma aplicação em vinícolas localizadas na Serra Gaúcha, 215p. Tese (Doutorado em Agronegócios) - Universidade Federal do Rio Grande do Sul, Porto Alegre, 2010.

CHARTER, M.; CLARK, T. Sustainable Innovation - Key conclusions from Sustainable Innovation Conferences 2003-2006 organised by The Centre for Sustainable Design. The Centre for Sustainable Design University College for the Creative Arts: 2007.

CHESBROUGH, H.; ROSENBLOOM, R. S. The role of the business model in capturing value from innovation: evidence from Xerox Corporation's technology spin-off companies. Industrial and Corporate Change, v. 11, n. 3, p. 529-555, 2002.

DAFT, R. L.; MARCIC, D. Understanding Management. Versailles: Thomson - South-Western, 2004. 
EIRIZ, V.; FARIA, A.; BARBOSA, N. Firm growth and innovation: Towards a typology of innovation strategy. Innovation: Management, Policy \& Practice, Maleny, v. 15, n. 1, p. 97-111, 2013.

GIL, A. C. Métodos e técnicas de pesquisa social, 6. ed. Atlas: 2008.

GLOBAL REPORTING INITIATIVE - GRI. 2006. Diretrizes para relatório de sustentabilidade. Disponível em < http://www.globalreporting.org>. Acesso em 15 outubro de 2010.

GUNDAY, G.; ULUSOY, G.; KILIC, K.; ALPKAN, L. Effects of innovation types on firm performance. International Journal Production Economics, v. 133, p. 662-676, 2011.

HALL, J.; VREDENBURG, H. The challenges of innovating for sustainable development. Mit Sloan Management Review, v. 45, n. 1, p. 61-68, 2003.

HANSEN, E; GROSSE-DINKER, F.; REICHWALD, R. Sustainability innovation cube: a framework to evaluate sustainability-oriented innovations. International Journal of Innovation Management, v. 13, n. 4, p. 683-713, 2009.

KIRON, D.; KRUSCHWITZ, N.; REEVES, M.; GOH, E. The Benefits of Sustainability-Driven Innovation. MIT Sloan Management Review, v. 54, n. 2, p. 69-73, 2013a. KIRON, D.; KRUSCHWITZ, N.; REEVES, M.; HAANAES, K.; GOH, E. The Innovation Bottom Line. MIT Sloan Management Review. Research Report, MIT Sloan Management Review and The Boston Consulting Group, p. 1-22, 2013b.

LEVY, D. L.; SZEJNWALD, B. H.; DE JONG, M. The Contested politics of corporate governance the case of the Global Reporting Initiative. Business \& Society, v. 49, 1, p. 88-115, 2010.

LOPEZ-VALEIRAS, E.; GOMEZ-CONDE, J.; NARANJO-GIL, D. Sustainable Innovation, Management Accounting and Control Systems, and International Performance. Sustainability, v. 7, n. 3, p. 3.479-3.492, 2015.

MARIMON, F.; ALONSO-ALMEIDA, M, D. M.; RODRÍGUEZ, M. D. P.; ALEJANDRO, K. A. C. The worldwide diffusion of the global reporting initiative: what is the point? Journal of Cleaner Production, v. 33, p. 132-144, 2012.

NEELY, A.; ADAMS, C.; KENNERLEY, M. The performance prism: the scorecard for measuring and managing business success. London: Prentice Hall, 2002.

NIDUMOLU, R.; PRAHALAD, C. K.; RANGASWAMI, M. R. Why sustainability is now the key driver of innovation. International Trade Forum, Geneva, n. 4, p. 10, 2009.

PRADO-LORENZO, J. M.; GALLEGO-ALVAREZ, I.; GARCIA-SANCHEZ, I. M. Stakeholder engagement and corporate social responsibility reporting: the ownership structure effect. Corporate Social Responsibility and Environmental Management, v. 16, p. 94-107, 2009.

RASCHE, A. Toward a model to compare and analyze accountability standards - the case of the UN global compact. Corporate Social Responsibility and Environmental Management, v. 16, p. 192-205, 2009.

SCHALTEGGER, S.; LÜDEKE-FREUND, F.; HANSEN, E. G. Business cases for sustainability: the role of business model innovation for corporate sustainability.

International Journal of Innovation and Sustainable Development, v. 6, n. 2, 2012. 
SCHALTEGGER, S.; WAGNER, M. Sustainable entrepreneurship and sustainability innovation: categories and interactions. Business Strategy and the Environment, v. 20, n. 4, p. 222-237, 2011.

SEEBODE, D.; JEANRENAUD, S.; BESSANT, J. Managing innovation for sustainability. R\&D Management, v. 42, n. 3, p. 195-206, 2012.

SKOULOUDIS, A.; EVANGELINOS, K.; KOURMOUSIS, F. Development of an evaluation methodology for triple bottom line reports using international standards on reporting. Environmental Management, v. 44, p. 298-311, 2009.

SMITH, A.; VOß, J.-P.; GRIN, J. Innovation studies and sustainability transitions: The allure of the multi-level perspective and its challenges. Research Policy, v. 39, n. 4, p. 435-448, 2010.

SZEKELY, F.; STREBEL, H. Strategic innovation for sustainability. IMD - International Institute for Management Development: 2012. Disponível em <http://www.imd.org>. Acesso em dezembro de 2013.

TARAN, Y. Rethinking it all: Overcoming obstacles to business model innovation. PhD thesis, Center for Industrial Production, Aalborg University, Aalborg, Denmark, 2011.

TARAN, Y.; BOER, H.; LINDGREN, P. A Business Model Innovation Typology. Decision Sciences, v. 46, n. 2, p. 301-331, 2015.

TEECE, D. J. Business Models, Business Strategy and Innovation. Long Range Planning, v. 43, n. 2-3, p. 172-194, 2010.

TSANG, S.; WELFORD, R., BROWN, M. Reporting on community investment. Corporate Social Responsibility and Environmental Management, v. 16, p. 123-136, 2009.

VILLAS BÔAS, H. C. A indústria extrativa mineral e a transição para o desenvolvimento sustentável. Rio de Janeiro: CETEM/ MCT/ CNPq, 2011.

WAGNER, M. The role of corporate sustainability performance for economic performance: A firm-level analysis of moderation effects. Ecological Economics, v. 69, n. 7, p. 1.553-1.560, 2010.

YIN, R. K. Estudo de caso: planejamento e métodos. Trad. Ana Thorell, 4. ed. Porto Alegre: Bookman, 2010.

Recebido em: 23-2-2017

Aprovado em: 30-08-2017

Avaliado pelo sistema double blind review.

Editor: Elmo Tambosi Filho

Disponível em http://mjs.metodista.br/index.php/roc 